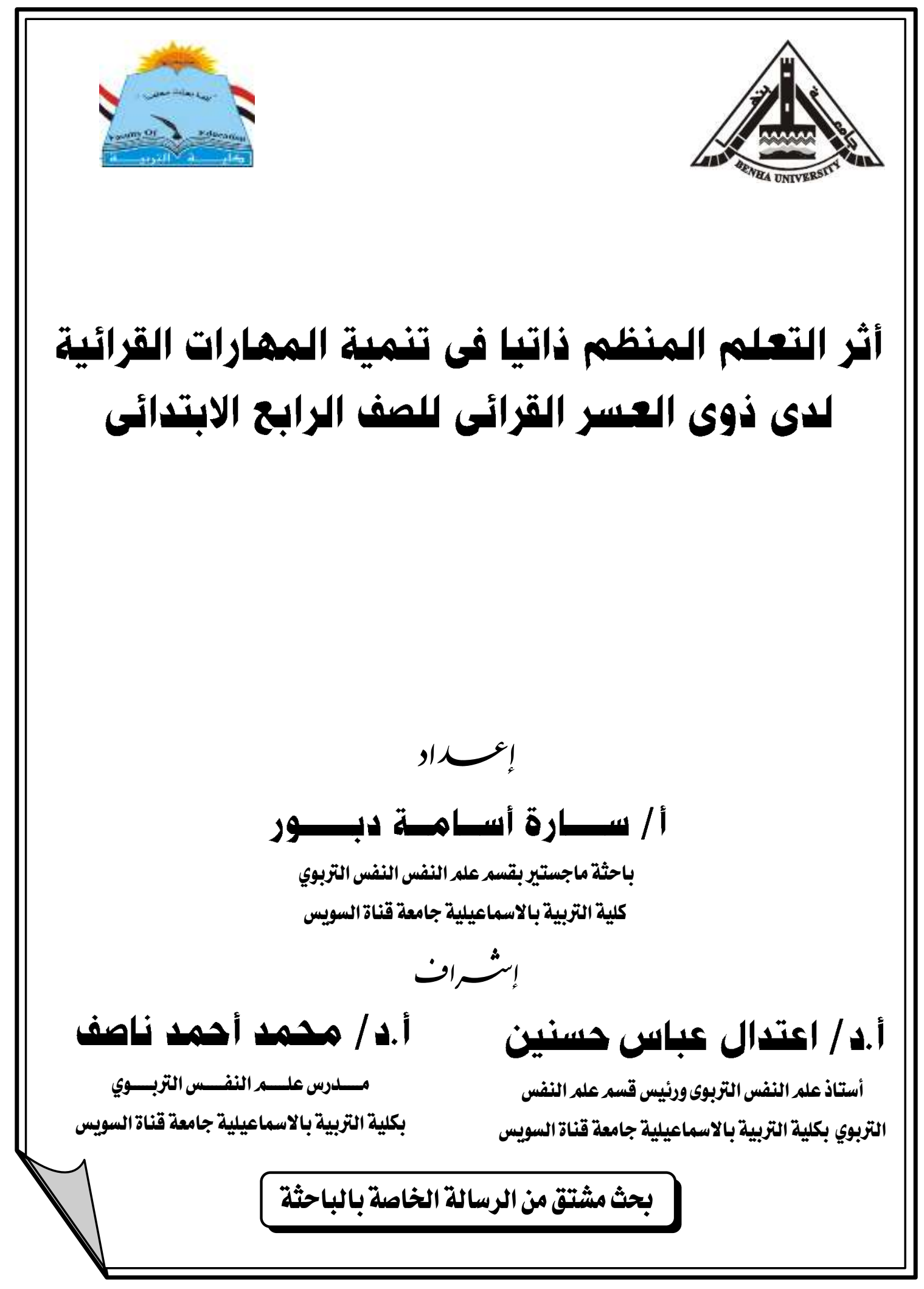




\title{
أثر التعلم المنظم ذاتيا فى تنمية المهارات القرائية لدى ذوى العسر القرائى للصف الرابع الابتائى لئى
}

\author{
إبـ

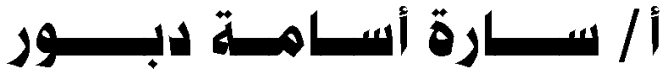

باحثة ماجستير بقسم عله النضس النضس التزبوي - كلية التربية بالاسماعيلية جامعة قناة السويس

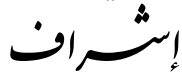

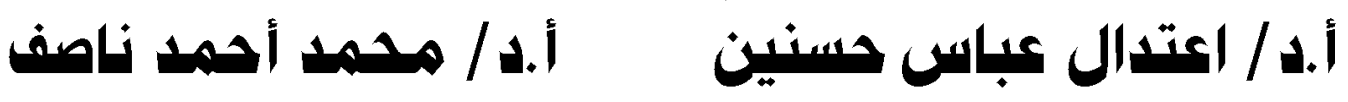

ملمرس عله النفس التزبوي

أستاذ عله النفس التربوى ورئيس قسم عله النفس بكلية التربية بالاسماعيلية جامعة قناة السويس عليس

التزبوي بكلية التربية بالاسماعيلية جامعة قناة السويس

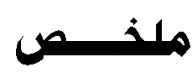

لقد شهدت العقود الأخيرة من القرن المنصرم تطوراً ملحوظاً فى مجال التدري، فلم يعد الاهتمام بالمعلومات هو الغاية الوحيدة من العملية التعليمية بل زاد الاهتمام بشكل ملحوظ بالتلميذ وذلك من خلال تشجيعه على القيام بمزيد من النشاط والتفاعل مع زملائه كمجموعة وكأفراد، وإتاحة

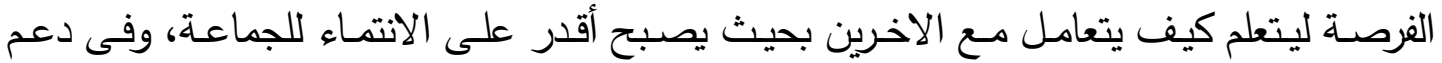

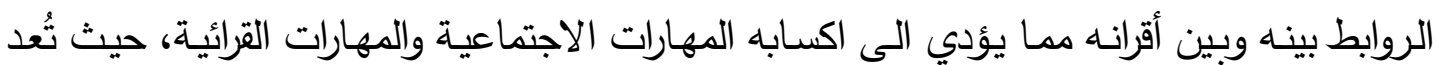

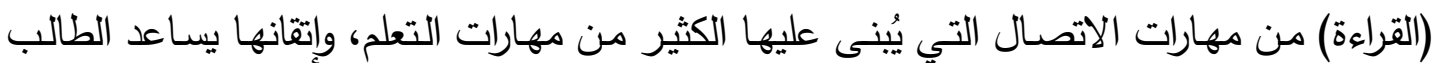

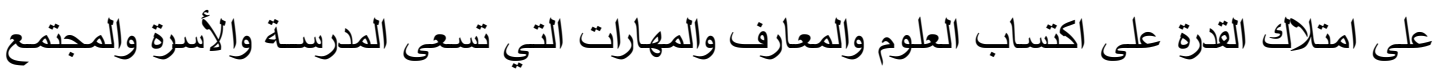

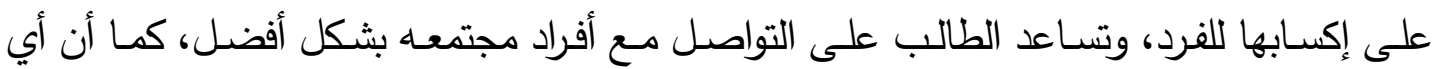
ضعف، أو خلل في (القراءة) يتبعه ضعف فئ مهارات التعلم والتواصـل الأخرى.

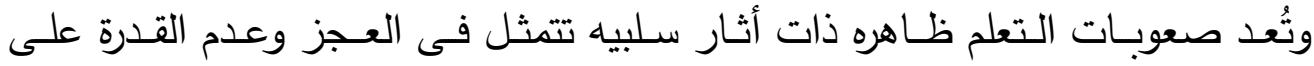
المتابعه وغيرها من المشاعر التى تتعكس فى صوره اضطرابات مختلفه وسلوكيات سلبيه مثل ونل التسرب من التعليم أوظاهرة الهروب أو الفقد التعليمى. ويرى كثير من علماء النفس أن أستراتجيات التعلم المنظم ذاتيا تبدو أكثر ارتباطاً بذوى لهو صعوبات التعلم، حيث يختلف كما وكيفا لدى العاديين من الأفراد. ويمكن تتميـه المهارات القرائيـه بأسـتخدام أسـتراتجيات التعلم المـنظم ذاتيـا وأن التعلم المنظم ذاتيا يكسب التلاميذ القدره على التعلم، ويدعم معارفهم وسلوكهم ووجدانهم من خـلال بالم ضبط تفكيرهم عند اكتسابهم للمعرفه والمهارات، كما يساعدهم على تصميم بيئات تعلم جديدة. وتحاول الدراسة الحالية التعرف على أثر التعلم المنظم ذاتيا فى تتمية المهارات القرائية لاى ذوى العسر القرائى للصف الرابع الابتدائى. 
تُعد (التراءة) من مهارات الاتصال التي يُبنى عليها الكثير من مهارات التعلم، وإتقانها

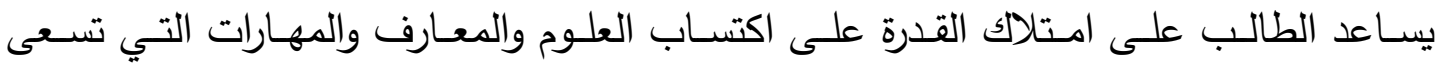

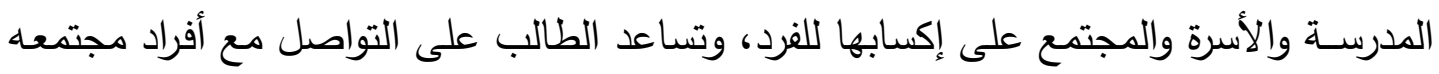

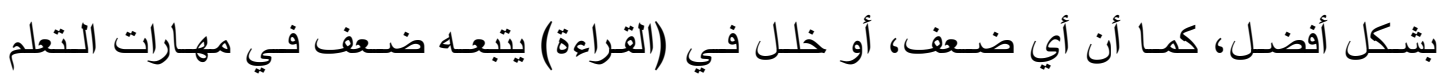

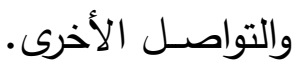

ومن معوقات تدريس القراءة وجود عينة من الطلاب لا يستطيعون تعلم القراءة أو

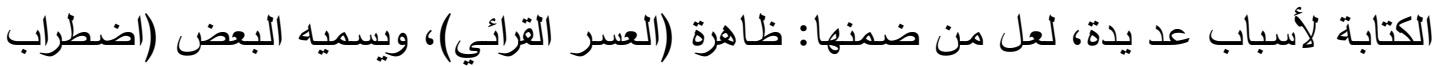

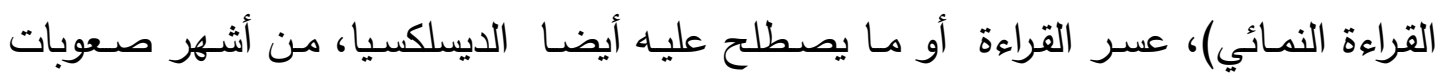

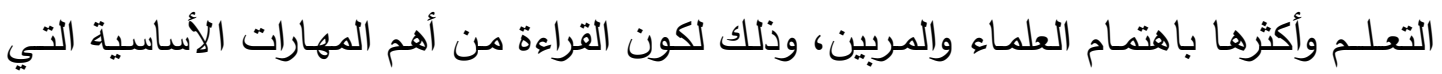

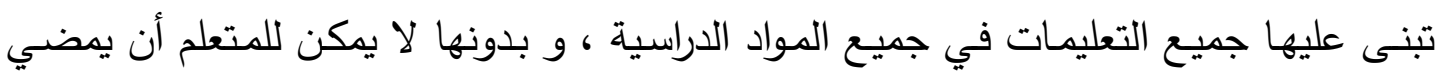

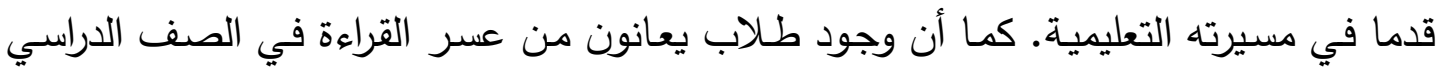
من شأنه التأثير على المستوى العام للطلاب، وهدر الكثير من الوقت والجهد في معالجة ظاهرة لا يُعْرف عنها الكثير في الأوساط الدراسية. تعد صعوبات التعلم ظاهره ذات أثار سلبيه تتمثل فى العجز وعدم القدرة على المتابعها

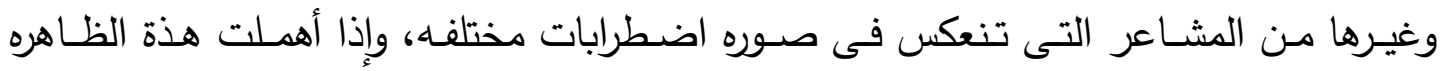

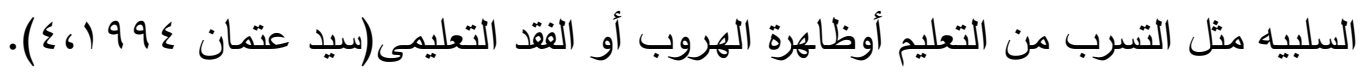
ويرى كيرك وكالفنت (0.1919 1) أن صعوبات تعلم القراءه تمثل نسبه كبيره من بين

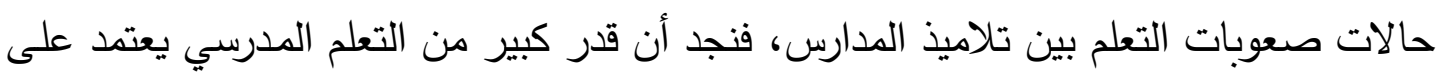

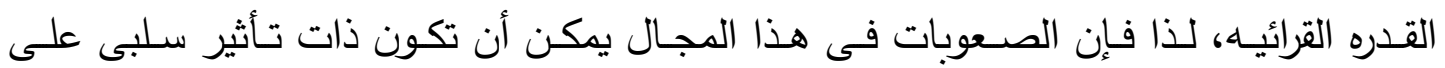
شخصيه التلميذ. وقد ذكر هـارس، وسـايبلى أسبابا كثيره لضـفف التقدم فى فهم القراءه، وتشمل هذة

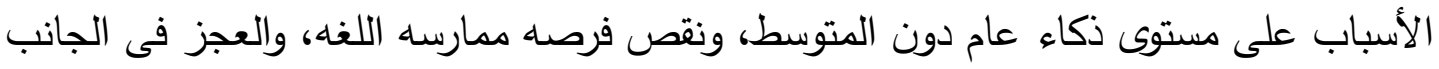
السمعى والنطق والتى تعمل جميعا على حصر وتحديد وتطور المفردات ـ إن القراء البطيئه كلمه - كلمه قد تسبب ضعفا فى الفهم فالطالب غالباً مايضطر إلى إعادة قراءه المادة المقرووها

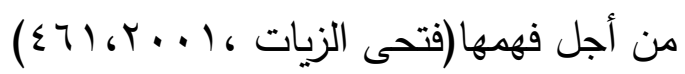


وقد اتجهت الدراسات والبحوث المعاصرة إلى التركيزعلى المشكلات والعمليات المعرفيـه ومـا وراء معرفيـه التى تقف خلف صـعوبات التعلم، وقد أستقطبت عمليـات مـاوراء المعرفيـه

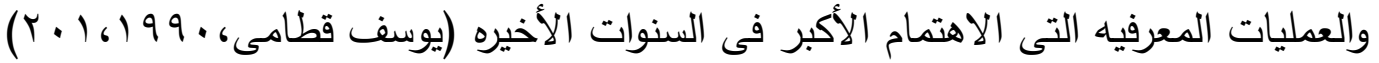

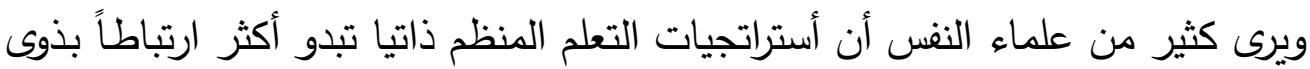

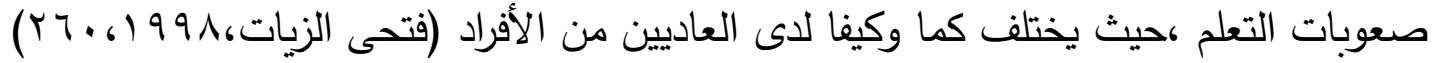

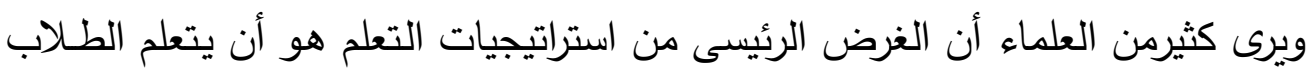

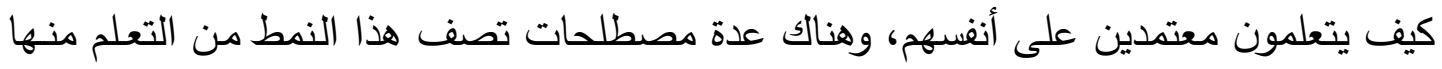
متعلم مستقل independent learner، ومتعلم استراتيجى strategic learner، ومتعلم منظم ذاتيًا regulated learner - self (جابر عبد الحميد، 999 1، 1 • • (ب)، فالطلاب في حاجة إلى استراتيجيات التنظيم الذاتى والتى تركز على العمليات المنظمة ذاتيًا والتى تتنبأ بالأداء الأكاديمى للطلاب (Zimmerman, 1994, 11) )، ومن ثم يجب أن يتعلموا كيف يستخدمون مدى واسعًا من الاستراتيجيات بشكلٍ مستقل داخل حجرة الدراسة. فبعض الاستراتيجيات تنظم

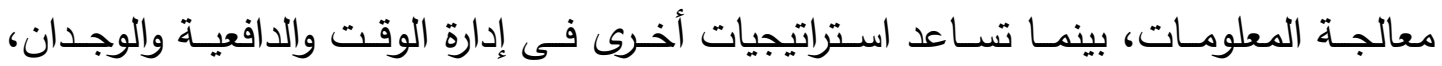

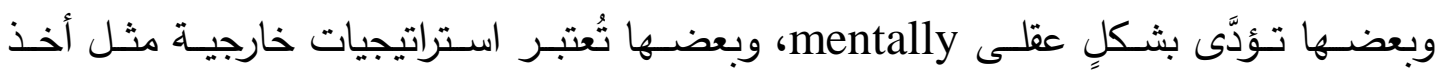
الملاحظات، وبعض الاستراتيجيات تكون محددة بالمواقف والمهام، بينما تُعتبر بعضها مُوجهة، ومُشجعة للطلاب على الاكتشاف والدراسة(Paris et al., 2001, 272-273)، والمهم هنا هو قـدرة الطـلاب علـى الاختيـار ، والـربط، والتتسـيق بـين هـذهـ الاسـتراتيجيات بطـرق فعالــة. (Bockaerts, 1999, 447)

أستخدم (هاريس وجراهام 994 (1) نموذجا للتنظيم الذاتى حيث أستخدم هذا النموزج

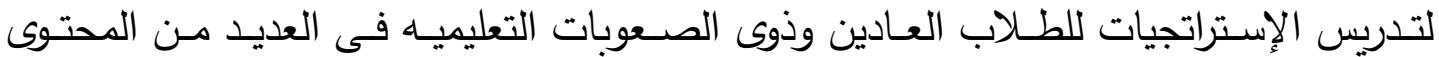
التعليمسه المختلفه (Swanson\&Delapaz,1988) ومن هنا يظهر الهدف الرئيسى من التعلم المنظم ذاتيا - هو - زياده وعى المتعلمين تجاه أنفسه كمتعلمين ووضعهم فى مواقف تدريبيه تتسم بالفاعليه، وجعل المتعلم يقظا، وأكثر قدره على تحسين مستوى تعلمه. وفى دراسه بويل (Boyle,1996) تشير إلى مدى تاثير إستراتجيات الخرائط المعرفيه فى تتميه مهاراه أستخدام أستخراج المعنى من الحرفى والمعنى الأستتاجى وتأثيره فى تتميـيه المهارات القرائيه. - المياه 
وأكـدت دراسـه سوانسـون وهوسـكين (Swanson\&HOSKING,1998) أن هنـاك

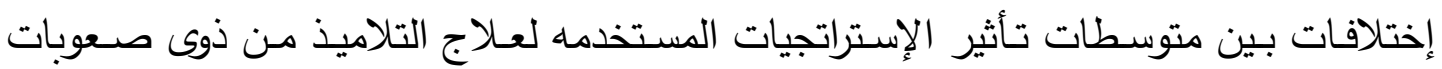

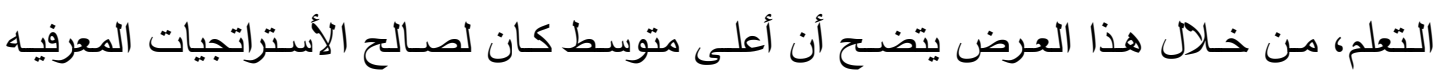

والتدريس المباشر (Swanson\&Hosking,1998)

وترى الباحثه فى ضوء ماسبق، يمكن تتميه المهارات القرائيها بأستخدام أستراتجيات

التعلم المنظم ذاتيا وأن التعلم المنظم ذاتيا يكسب التلاميذ القدره على التعلم، ويدعم معارفهم

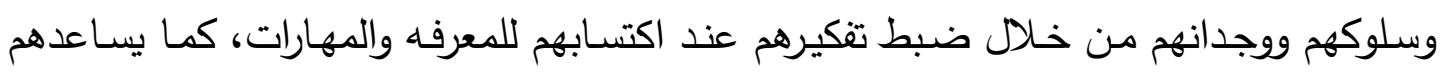

على تصميم بيئات تعلم جديدة

\section{مشكاستة السراسيسة:}

تتحدد مشكله البحث الحاليـه فى أنتشـار صـوبات التعلم بدرجه كبيره فى مدارسنا ومؤسساتتا التعليمه فى مختلف مراحل التعليم حيث لاحظ الباحث من خلال عمله فى مجال التدريس أن هناك عدد ليس بقليل من التلاميذ ينخفض مستوى تحصيلهم عن مستوى زملائهر

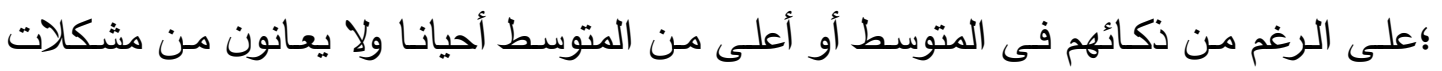

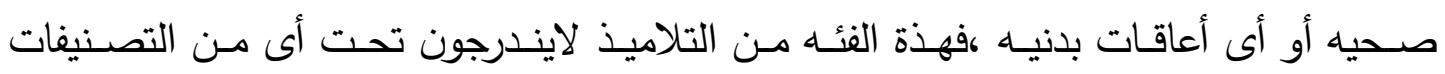

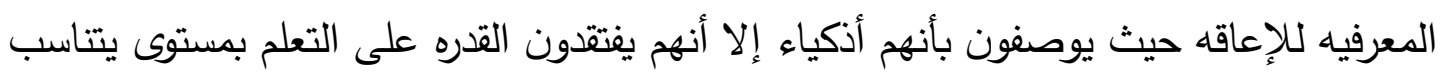
مع قدراتهم العقليه مما يترتب عليه تكرار رسوب، ومن ثم تسرب نسبه كبيره من التعليم، وأكد الكد التهاء

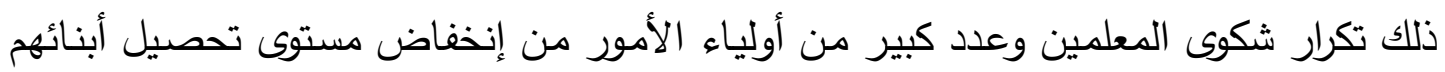

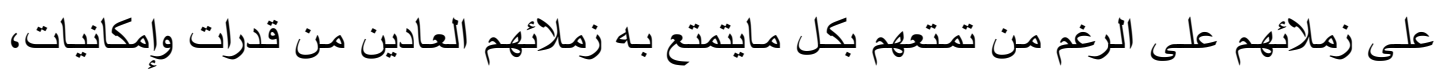

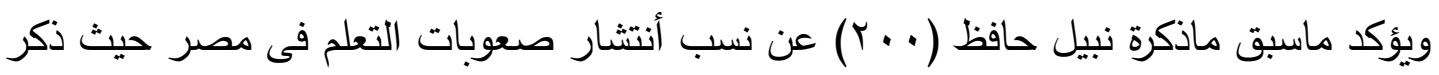

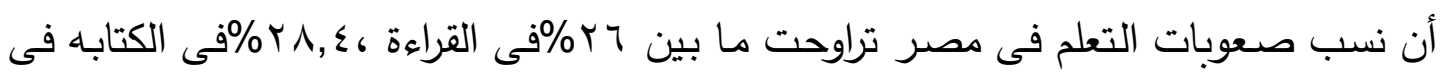

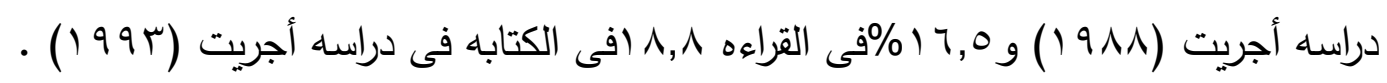

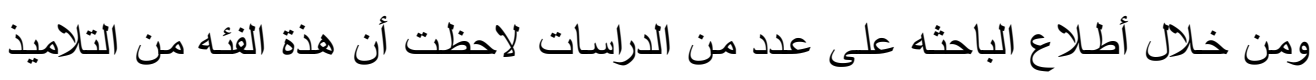

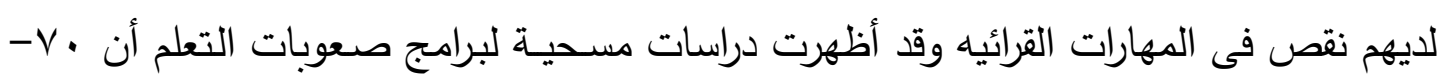

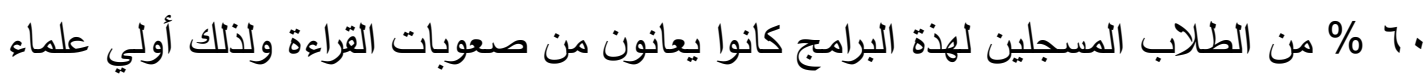

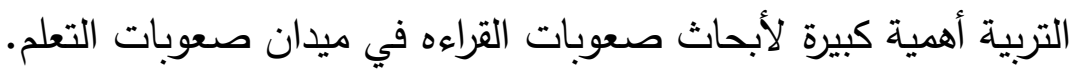


وقد أشـارت العديد من الدراسـات مثل دراسـة تورحبسون وآخرون (Toregeson et.al) وكيرك وكيرك (Kirk , Kirk نقلاً عن وبستر (Webster, 1998) إلي أن العديد من الأطفال

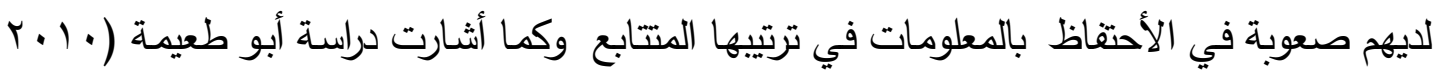

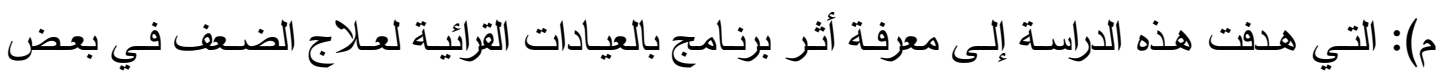
المهارات القرائية لاى تلاميذ الصف الرابع الأساسي في محافظة خان يونس.

\section{أهـــاف البدراسيسلة:}

تسعى هذه الاراسة إلي تحقيق الاهداف التالي: تهذف الاراسه الحاليه إلى الكثف عن: أثر برنامج تدريبى قائم على بعض أستراتجيات التعلم المنظم فى تتميه المهارات القرائيه

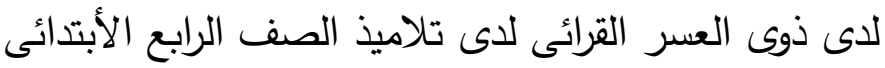

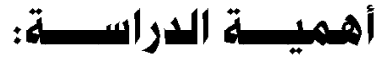

تتلخص أهمية الدراسة في النقاط التالية: 1- عمل برنامج يستخدم أستراتجيات التعلم المنظم يفيد طلبه المرحله الأبتدائيه. ץ- تتاول فئه صعوبات القراءة وهى فئه كبيرة فى مختلف مراحل التعليم وتحظى بأهتمام كبير من المربين وعلماء النفس. r- دراسه مهارات القراءه وتدريب التلاميذ عليها.

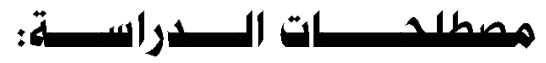

برنامج:program

يعرفه الباحث إجرائيا بأنها الأثر الناتج عن مرور التلاميذ (عينه الدراسـه) بخبرات البرنامج التدريبى القائم على أستراتجيات التعلم ومعرفه أثراها فى تتميه المهارات القرائيه لدى الدى

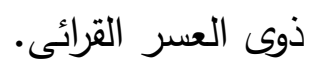

\section{التلاميذ ذوى صعوبات التعلم فى القراءة:}

\section{Students with learning Disabilities In Reading}

يعرفها الباحث بأنهم : هم التلاميذ ذوى الذكاء المتوسط أو الفوق متوسط الذ يـن

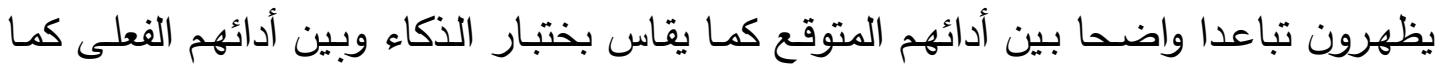


يقاس بأختبار التحصيل فى القراءة ولايعانون من أى إعاقه حسيه أو تخلف عقلى أو حرمان تربوى أو ثقافى أو اضطراب انفعالى لـ فئل

\section{التعلم المنظم ذاتيا: Self-Regulated learning strategies}

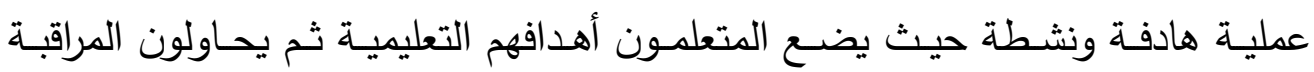

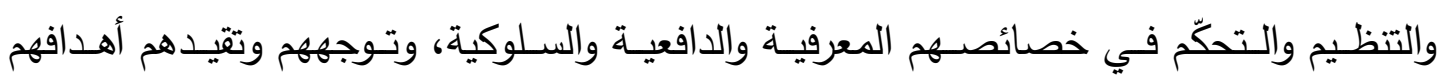
وخصائص السياق في البيئة التعليمية.

\section{Readingskills : مهارات القراءه}

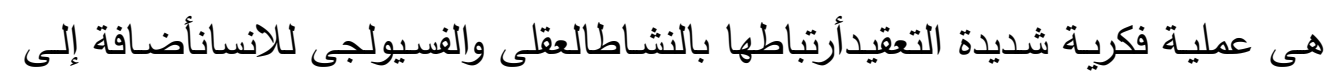
حسة البصروأداة النطق والحالة النفسيةوهى تقوم على أبعاد أربعـة التعرف والنطق -الفهم والنقدوالموازنة - وحل المشكلة.

\section{حسدود الـدراسيها}

تتحدد نتائج الاراسة الحالية بعدد من المحددات:

1- الحدود الزمانية: ترتبط بفترة تطبيق الدراسة خلال الفصل الدراسي الثاني للعام الدراسي

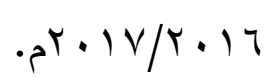

ץ- الحدود المكانية: تقتصر هذه الدراسة علي مدرسة سنتماى الإبتدائية المشتركة وتمثل المجموعة

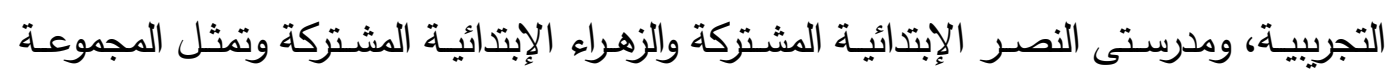
الضابطة، وهذه الدارس تابعه لإدارة ميت غمر التعليمية بمحافظة الدقهلية. r- الحدود الموضوعية: تتناول هذه الدراسة أثر التعلم المنظم ذاتياً فى تتمية المهارات القرائية

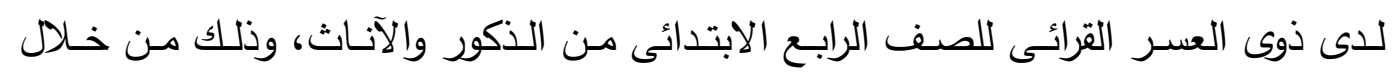
الأدوات والأساليب الإحصائية المستخدمة في الدراسة.

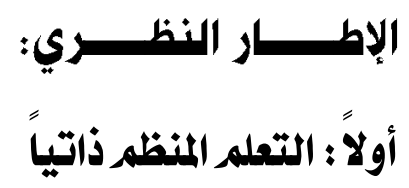

بدأت نظريات ونماذج التعلم المنظم ذاتياً منذ مطلح الثمانينات من القرن العشرين في

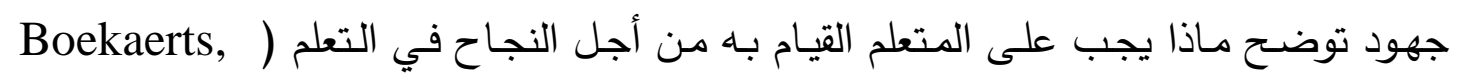
(Pintrich, \& Zeidner, 2000; Zimmerman, 2000 ويطلق على التعلم المنظم ذاتياً 
العديد من المصطلحات المترادفة ومنها التعلم الموجه ذاتياً Self-Detracted Learning، والتعلم المنظم ذاتياً Self-Regulated Learning، والتعلم الذاتي؛ وتستهدف الدراسة الحالية

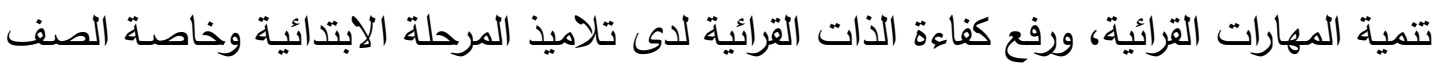
الرابع الابتدائي من خـلال الاعتماد على بعض استراتيجيات التعلم المنظم ذاتياً؛ فاستكمالاً لتتاول متغيرات البحث ستعرض الباحثة هذا العنصر (التعلم المنظم ذاتياً) من حيث مفهومها، ومكوناته، ومبادئه، وخصائص المتعلم المنظم ذاتياً، ودور التعلم المنظم ذاتياً في تتمية المهارات القرائية، والارتقاء بكفاءة الذات القرائية.

\section{مفهوم التعلم المنظظم ذاتياً}

يعد مفهوم التعلم الذاتي من المفاهيم الحديثة التي نالت اهتمام كثير الباحثيين في علم

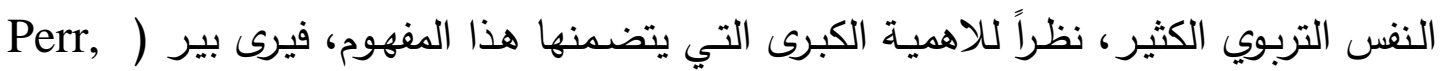
106 والخطط التى يتم اختيارها، أو تكوينها من بين عدة بدائل متاحة لتدبر نوع معين من المباحثات

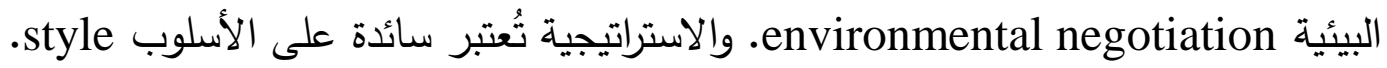

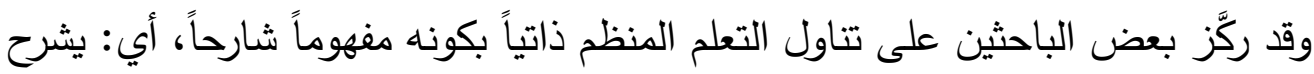

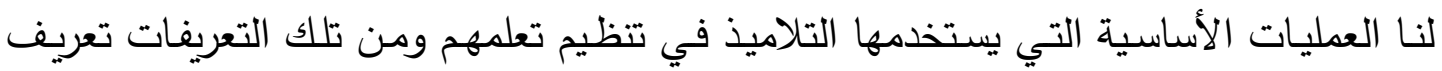

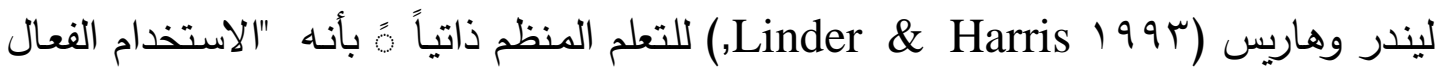

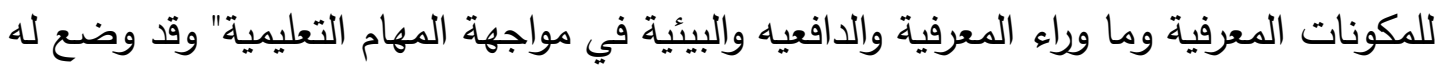

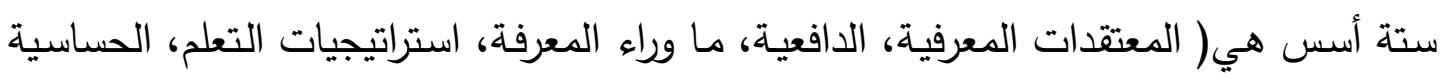
للموقف، الضبط البيئي). ومفهوم التعلم المنظم ذاتياً يُشير إلى الدرجة التى يكون عندها الأفراد مشاركين نشطين

بشكلٍ ما وراء معرفى، ودافعى، وسلوكى فى عملية تعلمهم ( (Zimmerman, 1994, 3.

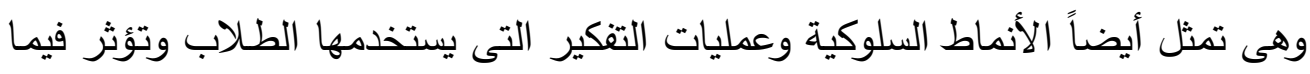

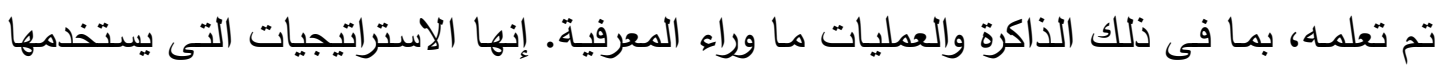

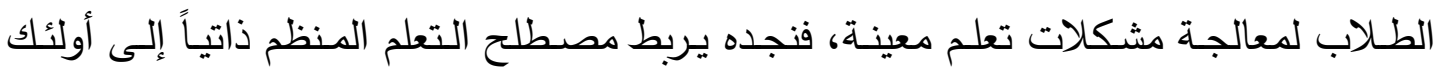
المتعلمين الذين يستطيعون القيام بأربعة أشياء مهمة وهي: فئهي: • أن يشخص موقفاً تعليمياً تشخيصياً صحيحاً ودقيقاً. 
• أن يختار استراتيجية تعلم لمعالجة مشكلة التعلم المطروحة.

$$
\text { • - أن يراقب فاعلية هذه الإستراتيجية. }
$$

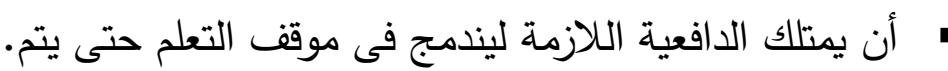

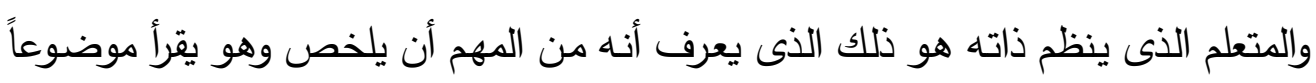

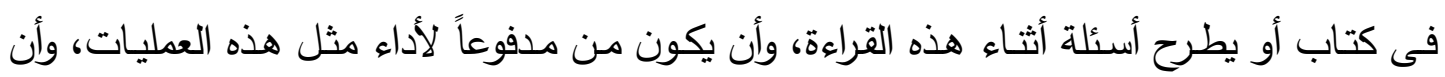

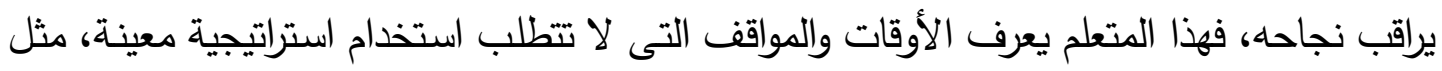

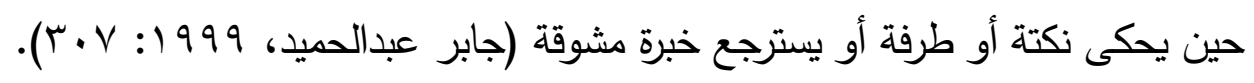

\section{ثانياً: المهــــــــارات القرائيـــة :}

لقد حظي تعليم القراءة والكتابة على المستوى العالمي باهتمام كبير ، واهتم كثير من

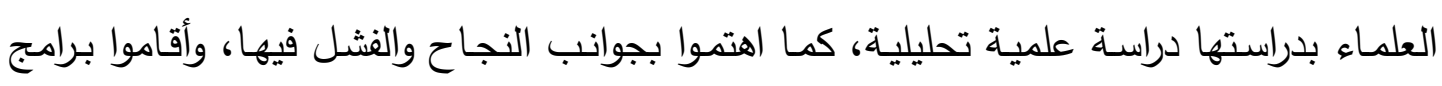
لدراسة حالات التأخر والضعف فيها، وكانت حصيلة تلك الجهود رصيدا ضخما من المعلومات

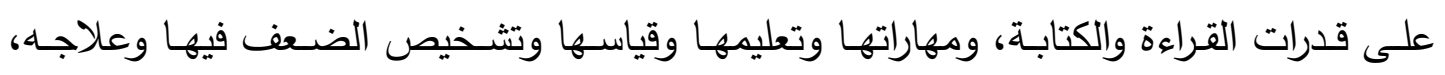

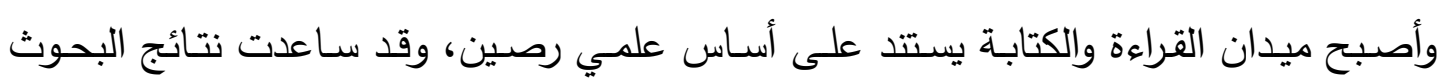

$$
\text { التربوية في إثراء هذا المجال. }
$$

وبالرغم من الجهود التي يبذلها المسئولون عن العملية التربويـة والمهتمون بتطوير التهاء

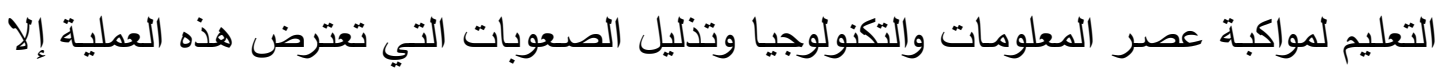

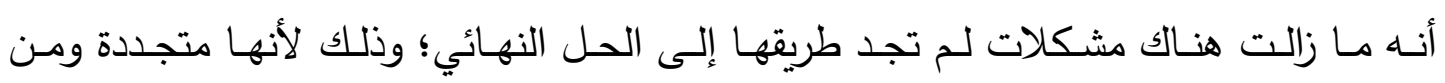

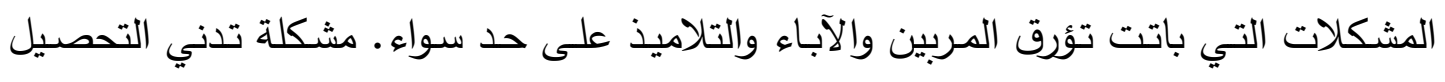

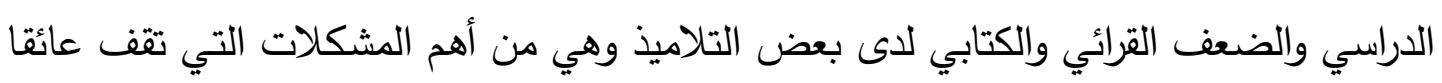

$$
\text { أمام التعليم (سعد علوان حسن، ب. . . ب، ـ ()). }
$$

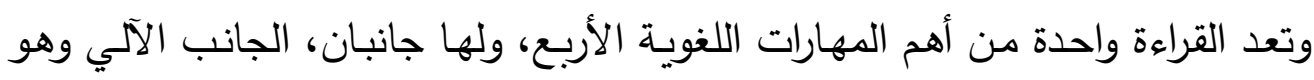

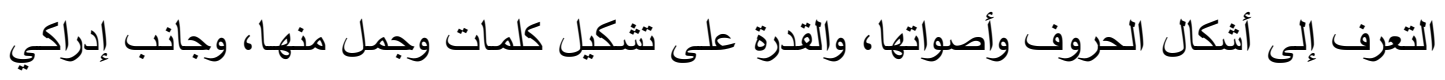

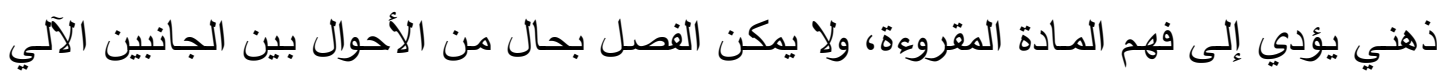

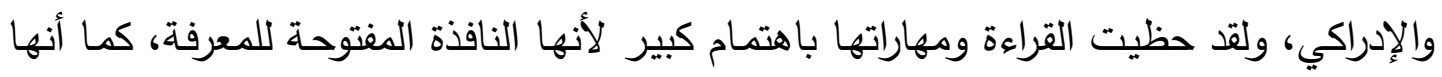

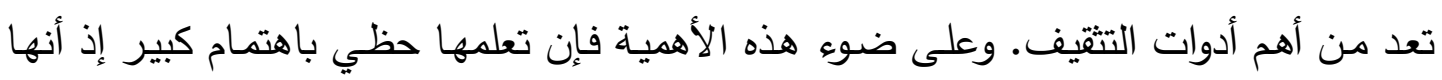

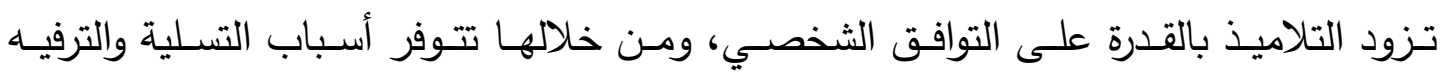


والاستمتاع من خـلال القصص والكتب، وتتمي لديهم العديد من المهارات أيضاً. (مصطفى

$$
\text { رجب، }
$$

لذلك فالقراءة تعد من أهم مهارات اللغـة التي تعلم في المدرسـة. وهي تحتوي على ألى

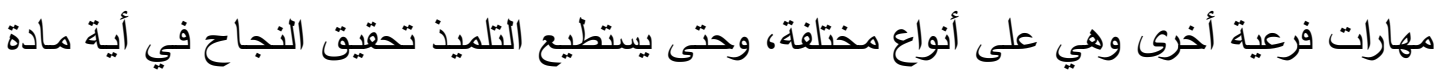

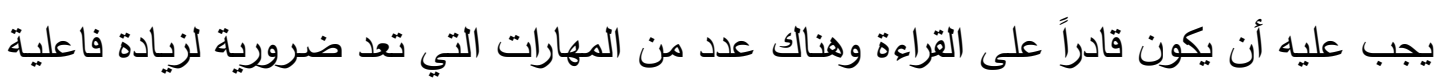

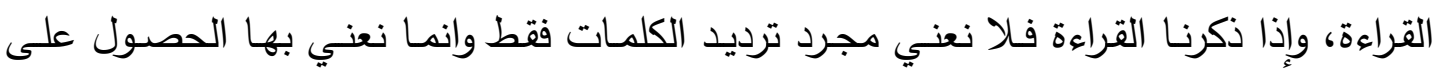

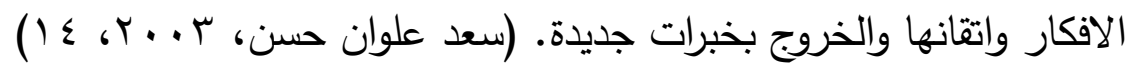

\section{مفهـــــوم القــــــاءة}

تعرف القراءة بأنها "عملية عضوية نفسية، يتم فيها ترجمة الرموز المكتوبة (الحركات -

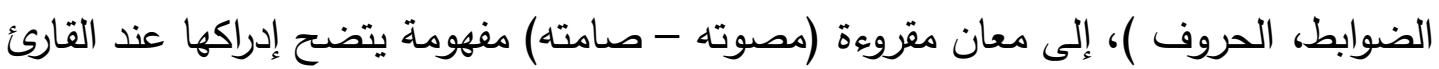

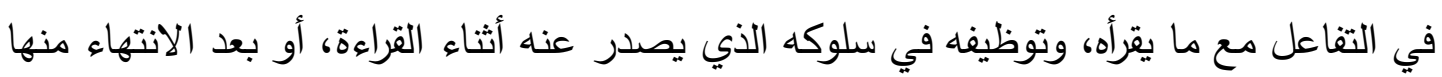

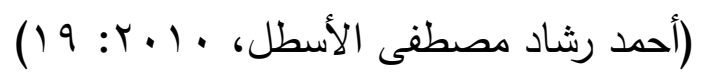

وكذلك تعرف بأنها "عملية انفعالية، دافعهاه تثمل تفسير الرموز، والرسوم التي يتلقاها القارئ عن طريق عينية، وفهم المعاني، والربط بين الخبرة السابقة، وهذه المعاني، والاستنتاج،

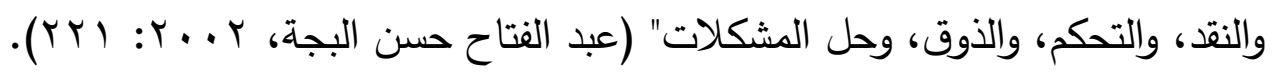

\section{أهميـــــة القـــــاءة}

تعد القراءة غذاء الروح والعقل، ويكفيها شرفاً أنها الكلمة الأولى التي نزل بها جبريل

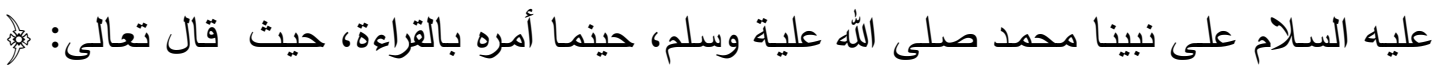

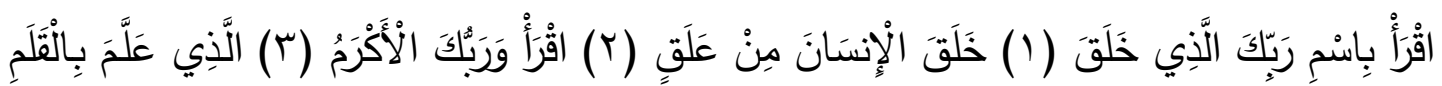

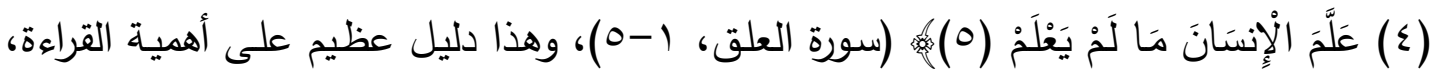

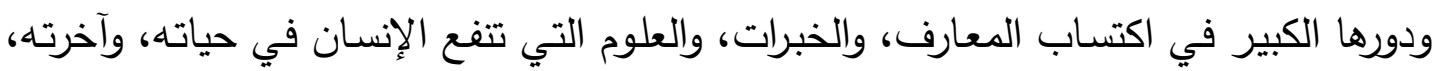

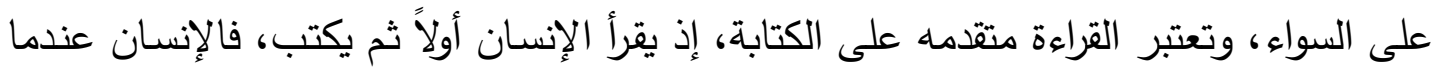
يتقن القراءة أحرفاً، وكلمات، وصورا ذهنية، تقوم اليد برسم ذلك كله على صفحات الدفتر .

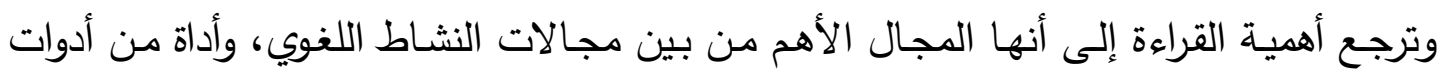

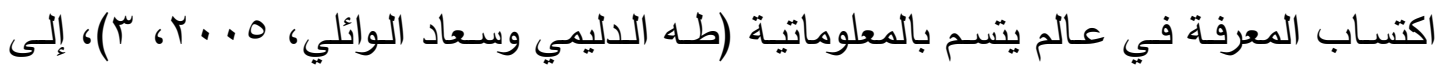

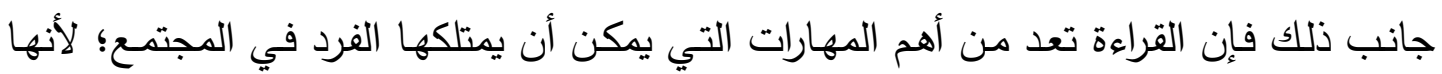


وسيلة التفاهم، والاتصال، والسبيل إلى توسيع آفاقه العقلية، ومضاعفة فرص الخبرة الإنسانية،

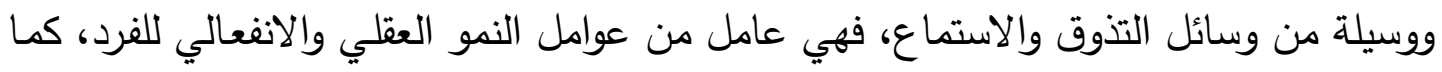

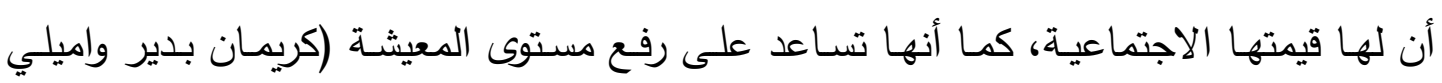

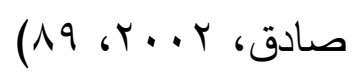

\section{ثالثا :المهارات القرائية}

كانت القراءة قديماً تعني قدرة القارىء على النطق بالألفاظ والعبارات بصوت مسموع،

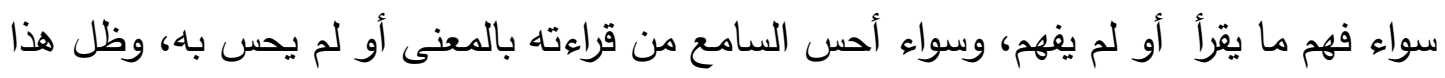
المفهوم سائداً حتى بداية القرن العشرين، وقد اختفى هذا المفهوم للقراءة، وحلت محله مفاهيم أخرى تتاسب تطور الحياة، ومن هذه الدفاهيم مفهوم (ثورندايك) للقراءة، حيث وجد ان النقاء القراءة

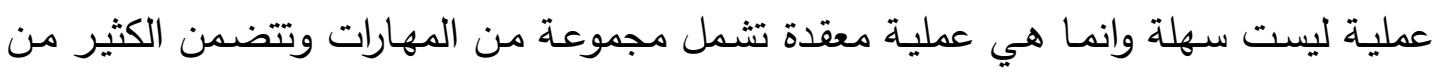

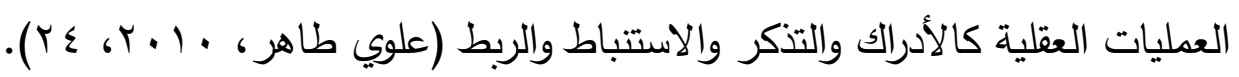
وتثمل الدراسة الحالية على المهارات القرائية التالية:

\section{أ) مهـــارة الفهـــم:}

الغاية الأساسية من تعليم القراءة هي الفهم الجيد وهذا ما أتفق عليه في اصول تدريس

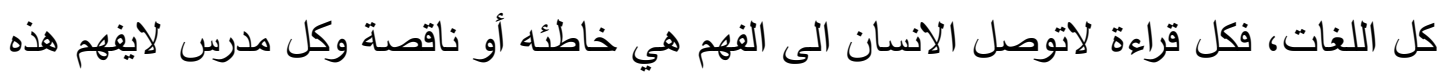

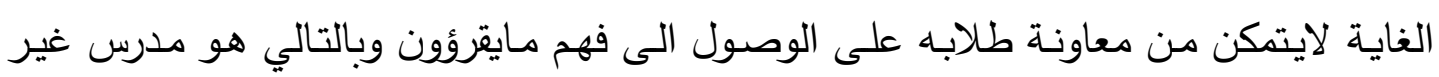

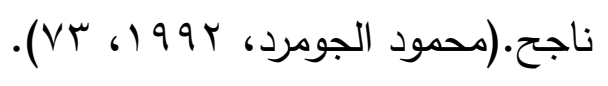

وتتوقف درجة الفهم القرائي على مدى معرفة الطالب بالكلمات الجديدة في النص، المقروء فكلما كان الطالب قادرآ على معرفة دلالات الكلمات زادت قدرته على فلى فهم النص، وهذا يتوقف على حد كبير عما يختزنه الطالب في ذاكرته من محصول لغوي أو ثروه لغويـه تؤهله

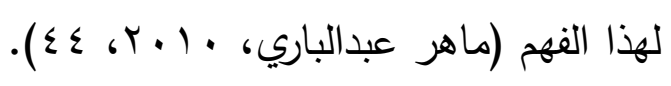

\section{ب) مهـــارة السر عـة:}

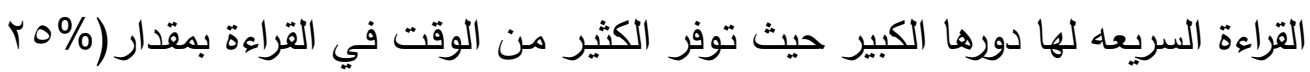
او •0 \%) وسرعة القراءة شيء مهم جدا وقد تكون غير مجدية إن لم تكن مصحوبة بعنصر الفهم، اذ ان الفهم هو الأسـاس في القراءة وان الغرض مـن القراءة هو فهر فهم الطالب لهـا يقرأ 
وهدفها هو تتمية القدرة على تتبع مايقرأ وتفسيره وفهـهـ كما أشار كل من (مصطفى فهمي،

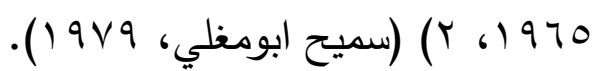

فالسرعة القرائية يجب أن تكون بين البطء المعيب والإسـراع المخل ولا ياتي هذا إلا

بكثرة تدريب المتعلمين على مشاهدة الكلمات وتقليبها في جمل وتراكيب. (عبد الفتاح البجها،

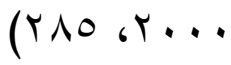

\section{ج) مهــارة الـدقـــة:}

ولكي يستطيع المتعلم أن يتحدث بدقه فلابد أن يكون لديه القدرة اللغوية ويكون مدركا

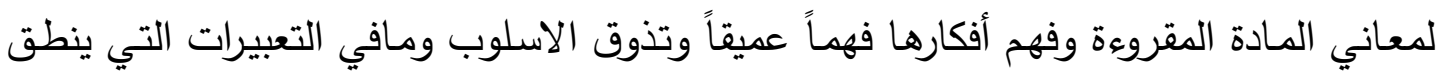
بها من جمال وفن. (سيف الاركي، V. . Y.، ع)

وهناك مهارات كثيره ومتتوعة ومتداخلة للقراءة، ذلك أنه من المعروف أن أن القراءة عبارة

عن مجموعة من المهارات التي يجب على القارئ المجيد الإلمام بهذه المهارات، لكي تكون القراءة سليمة صحيحة ويمكن حصر تلك المهارات كما ركز عليها التربويون وذكرها عبدالفتاح

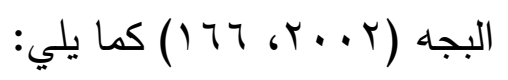

• قراءة الكلمات قراءة صحيحة من الناحية المعرفية (بنية الكلمة)، ومن الناحية اللغوية (حركة

$$
\text { الإعراب أخر الكلمة) وذلك حسب موقعها من الجملة. }
$$

• ت تغير نبرة الصوت بحسب المعنى : كالاستفهام والإخبار والطلب.

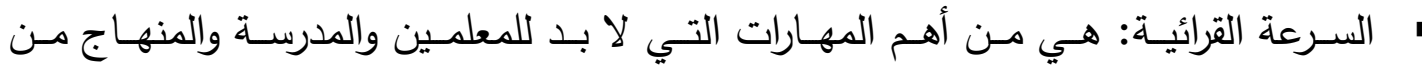

$$
\text { الحرص على تحقيقها. }
$$

إكسـاب التلاميذ عـادات القراءة الصـحيحة ومهاراتها المتمثلـة في سـلامة النطق وإخراج الحروف من مخارجها وجودة الإلقاء، وفهم المقروءة والاستماع له. إثراء معجمات الأطفال اللغوية بالأساليب والألفاظ.

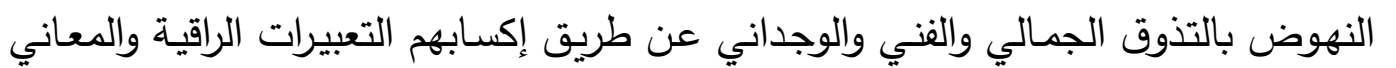

$$
\begin{aligned}
& \text { البارعة والصور الخلابة. } \\
& \text { • القدرة على الاستيعاب الكلي للمقروء. }
\end{aligned}
$$

قدرة المتعلم على التركيز وجودة التلخيص للمادة المقروءة إضـافة إلى القدرة على التذكر لعرك والتحصيل. 


$$
\text { • وقد أضاف طه الدليمي وسعاد الوائلي (0 . . r،ه) إلى تلك المهارات: }
$$

• حركة العين أثناء القراءة ووضعية القارئ.

وتوجد مجموعة من الدراسـات والبحوث السـابقة التى تتاولت المهارات القرائية بالبحث

والدراسـة، ومن هذه الدراسات دراسـة انتجي وآخرون (Antje, etal, 2015) والتى هدفت إلي وني التعرف على مهارات القراءة والهجاء لتلاميذ الصف الثالث فى المانيا وتكونت عينة الدراسـة من ( ૨^9) والهجاء لدى التلاميذ ترجع الى مستوى المدرسة، والوضع الاجتماعي والاقتصادي. بينمـا هدفت دراسـة جسيكا (Jessica, 2015) الى التعـرف على المهارات القرائيـة

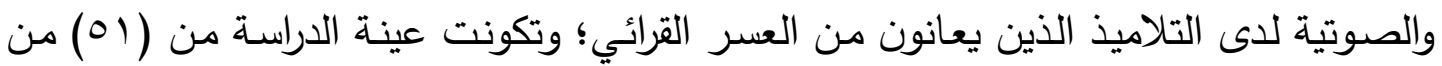
التلانيذ ذوى العسر القرائي؛ وتوصلت الدراسـة إلى ضعف المهارات الصسوتية، فى حين كانت المهارت القرائية على قدم المساواة مع الضوابط الصوتية، وتتبأ القدرات الصوتية على تحقيق مهارات القراءة التي تتناسب مع المستوى التتموي والصوتي.

\section{منهج وإجراءات الدراسة:}

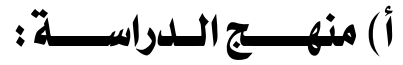

تستخدم الباحثة في الدراسة الحالية المنهج شبه التجريبي الذي يهدف إلى معرفة أثر المتغير المستقل (التعلم المنظم ذاتياً) في المتغير التابع (المهارات القرائية)، للتلاميذ ذوي العسر القرائي بالصف الرابع الابتدائي.

\section{ب) التصميير التجريبي:}

تستخدم الباحثة في الدراسـة الحالية التصميم شبه التجريبي ذوى المجموعتين التجربيية والضـابطة، والذي يعتمـد علـي القيـاس القبلي والبعدي للمجمـوعتين؛ وذلك باسـتخدام طريقـة التدريس العاديـة على العينـة الضـابطة, وطريقة التدريس القائمـة على التعلم المنظم ذاتياً على العينة التجريبية.

\section{وبن}

تكونـت عينـة الدراسـة الأساسـية مـن ( • ج) تلميذاً وتلميذة مـن تلاميذ الصـف الرابـع الإبتـدائي ذوي العسـر القرائي مـن ثـلاث مـدارس تابعـة لإدارة ميـت غمـر التعليميـة بمحافظــة 


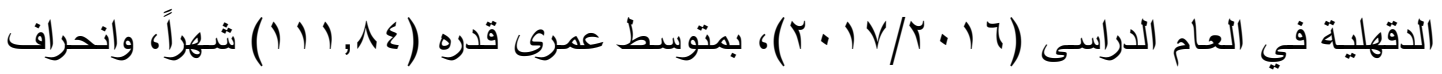

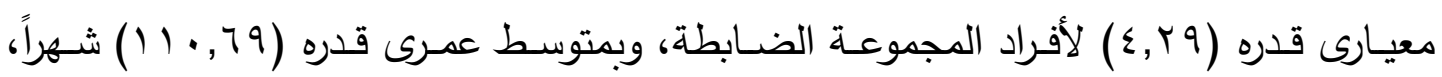
وانحراف معيارى قدره (1, (Y, لأفراد الهجموعة التجريبية، وقد تم اختيار هذه العينة من عينة

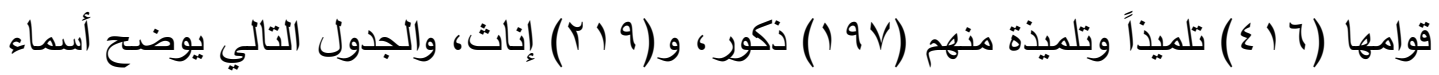
المدارس وعدد تلاميذ العينة الكلية المأخوذة من كل مدرسة.

\section{إجــراءات الـدراسيسة:}

البرامج والأساليب الاحصائية المستخدمة في التحليل: استخدمة الباحثة الاساليب التالية:

$$
\text { • - المتوسطات والانحرافات المعيارية. }
$$

• اختبار "ت" (Independent Sample T- Test)

Paired Samples T- Test) اختبار "ت

\section{نت}

توصلت الاراسة الحالية الى النتائج الآتية:

توجد فروق داله إحصائياً بين متوسطى درجات تلاميذ المجموعة التجريبية والمجموعة الضابطة في مهارات القراءة فى القياس البعدى لصالح تلاميذ المجموعة التجريبية.

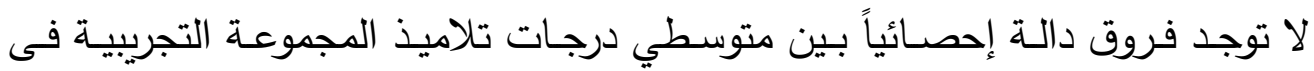
القياسين البعدي والتتبعي.

\section{مناقشة النتائج والتعليق عليها:}

\section{أولاً: نـنائج الفر ضر الأول:}

ينص الفرض الأول على: "توجد فروق داله إحصائياً بين متوسطى درجات تلاميذ المجموعة التجريبية والمجموعة الضابطة في مهارات القراءة فى القياس البعدى".

وللتحقق من هذا الفرض تم استخدام اختبار "ت" (Independent Samples t test) عينات مستقلة, والجدول التالي يوضح ذلك. 
جدول (ir)

\section{قيمة" ”"ودلالتها الإحصائية للفروق بين متوسطى درجات القياس البعدي}

للمجموعتين التجريبية والضابطة في مهارات القراءة

\begin{tabular}{|c|c|c|c|c|c|c|c|c|}
\hline الدلامة & "ق" قيمة" & التأثير & الحرية & الالتعراقيات & المتوبط & || الاثراد & المجموعة & القهرانية الماتية \\
\hline \multirow{2}{*}{$\because+1$} & \multirow{2}{*}{ Ta.00 } & \multirow[b]{2}{*}{.97} & \multirow[b]{2}{*}{01} & 1.00 & 74.9 & r. & التجريبية & \multirow{2}{*}{ هوالقهم القراني } \\
\hline & & & & T.1: & 17.97 & $r$. & الضانطة & \\
\hline \multirow{2}{*}{$\because+1$} & \multirow{2}{*}{ - 4.17} & \multirow{2}{*}{$.9 v$} & \multirow{2}{*}{$0 \mathrm{~A}$} & T.rt & $V \pm .4 T$ & $r \cdot$ & التجريبية & \multirow{2}{*}{ ههارات الأنطق } \\
\hline & & & & T.AI & r9.07 & $r$. & الضانطة & \\
\hline \multirow{2}{*}{$\because+1$} & \multirow{2}{*}{0.1.} & \multirow{2}{*}{.99} & \multirow[t]{2}{*}{00} & T.. 0 & $11 . .01$ & $r$. & التجرييية & \multirow{2}{*}{ الثربة الكلية } \\
\hline & & & & $5 . T A$ & $0 \% .04$ & $r$. & الضصايطة & \\
\hline
\end{tabular}

يتضـح من الجدول السـابق أن قيمـة "ت" للفروق بين متوسطى درجـات المجموعتين

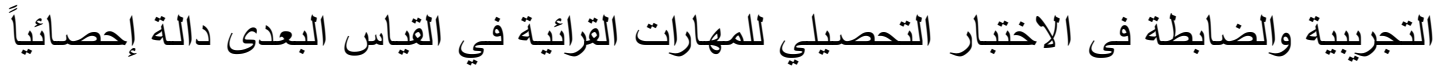

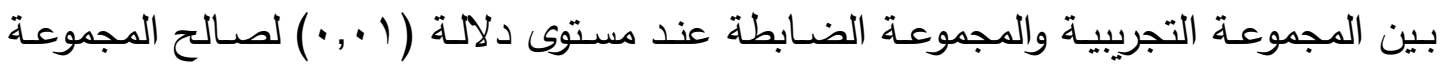

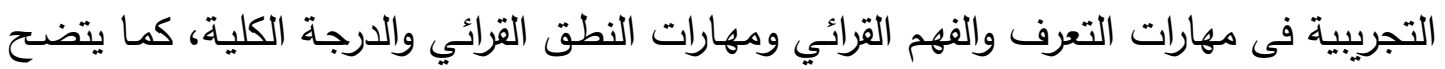

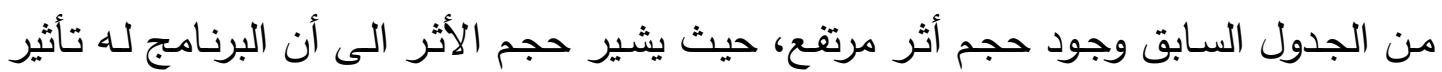
كبير فى تعلم التلاميذ المهارات القرائية. وبالتالي يتم قبول الفرض الأول حيث توجد فروق داله إحصائياً بين متوسطى درجات

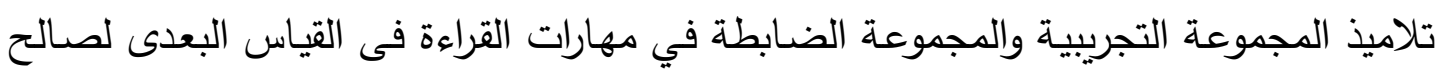

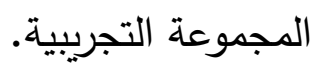
وتتفق هذه النتيجة مـع النتائج التى توصلت إليها دراسـة خيري المغازي (بو9 ())،

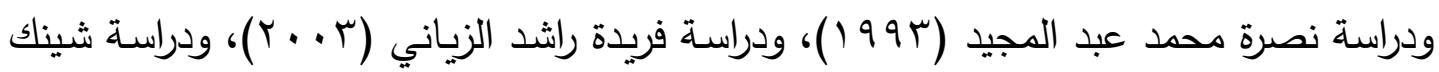

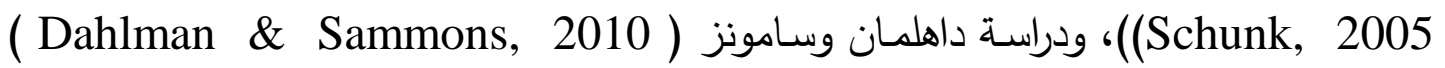

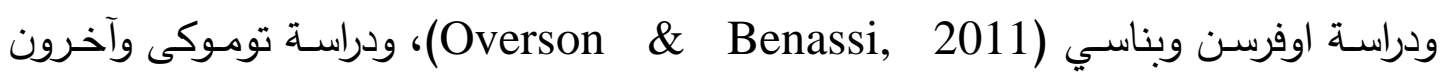

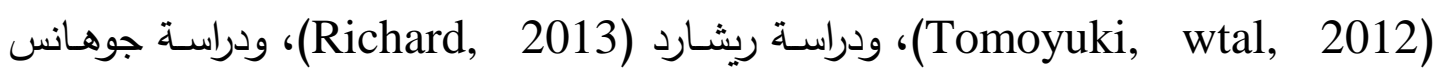
وآخرون (Johannes, etal, 2015)، ودراسة الاي دين (Alaeddin, 2017)، ودراسـة

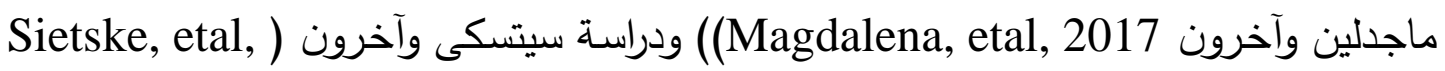

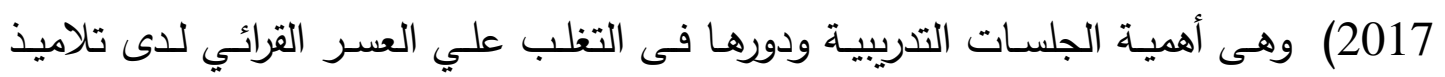

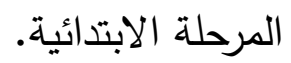


ومـا توصلت إليه دراسـة انتجي وآخرون (Antje, etal, 2015)، ودراسـة جسيكا (Jessica, 2015)، ودراسة فيسكى وآخرون (Vickie, etal, 2015)، ودراسة ساراه وآخرون (Sarah, etal 2016)، ودراسة ريناى وجوانى (Renae \& Joanne, 2016)، ودراسة الاي دين (Alaeddin, 2017) من أن تتوع المثيرات والتحديات المثيرة وتقييم المهمـة يحسن المهارات القرائية لدى التلاميذ. وتفسر الباحثة هذه الفروق بين المجموعتين التجريبية والضابطة بالإجابة عن التساؤل

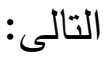

لمساذا وجدت فروق داله إحصـائياً بين متوسطى درجات تلاميذ المجموعـة التجريبيـة

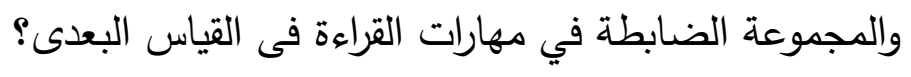

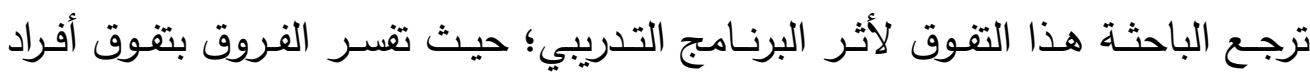

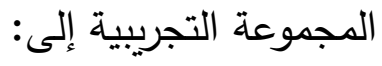
زيادة شعور التلاميذ بفعاليتهم أثناء الجلسات وقدرتهم على الممارسة الفعلية لما تم تدريبهح

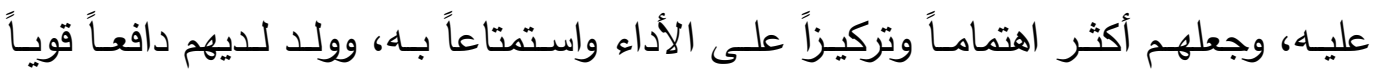

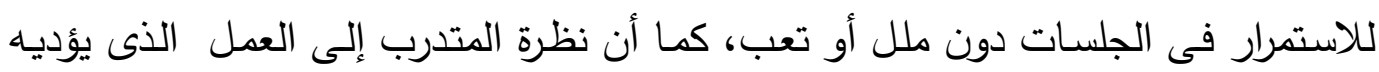

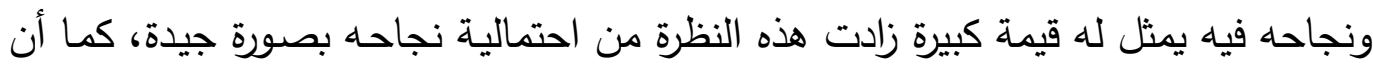
إتاحة الفرصة للمناقشة والحوار جعلتهم يستمتعون بالعمل، وقد أسهم فى ذلك إتاحة الفرصة

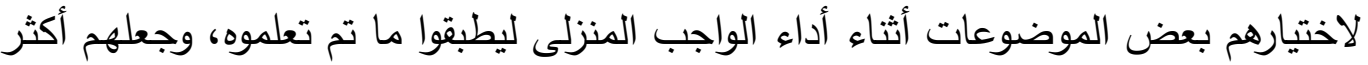
مثابرة وأكثر إحساساً بقيمة ما تعلموه. مـواجهتهم بمواقف غير مألوفـة لديهم تحتاج للتدقيق والتركيز فـى الإجابـة عن الأسئلة

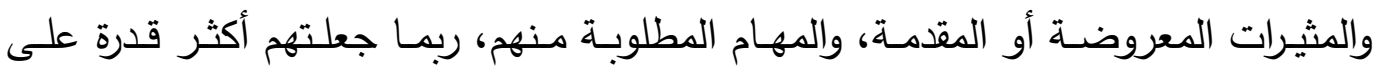

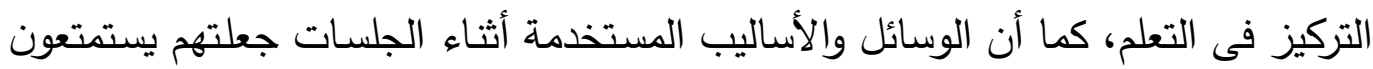

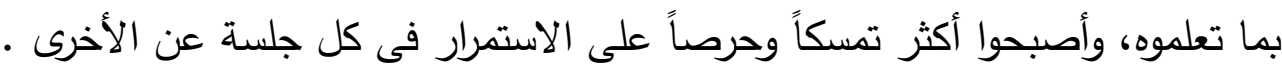

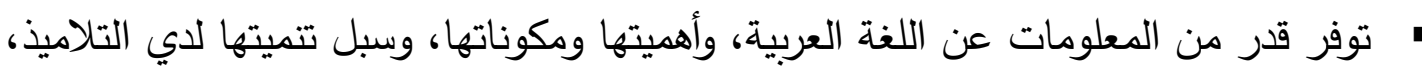

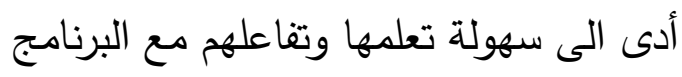
التعزيز اللفظى الموجب والمناسب والمناخ السائد بقاعة الجلسات، الذئى تتميز بالاحترام والاهتمام وتقبل أفكار المشاركين ومشاعرهم، وإحساسهم بأن جميع أفكارهم الخاصة بتتفيذ لتهني 
المهام والأنشطة المتضمنة فى البرنامج محل تقدير واهتمام، وتوفير بيئة حقيقية مناسبة لاستثارة وتحسن تعلمه للمهارات القرائية. عدم تقديم المكافآت المادية جعلهم يعملون من أجل العمل ذاته، وبالتالى كانوا يثابرون

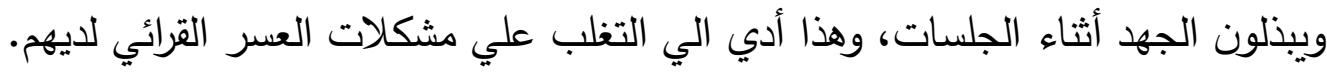

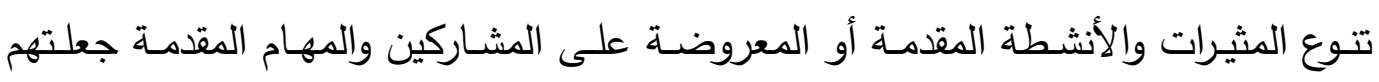
يهتمون بالتركيز والاستمتاع به والمثابرة أثنائه، وهذا يعنى تحسن المهارات التهات القرائية لديهم.

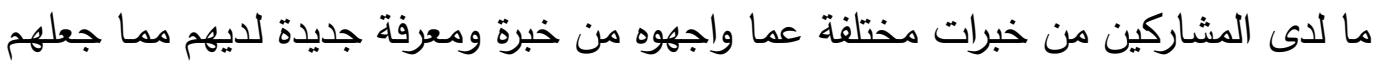

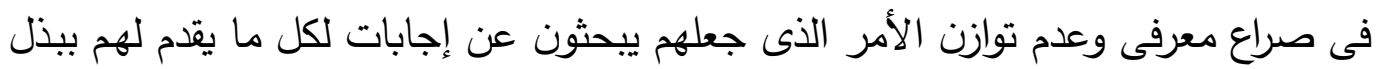
المزيد من الجها والمثابرة، وهذا ينتج عنه التغلب علي مشكلات العسر القرائي لديهم.

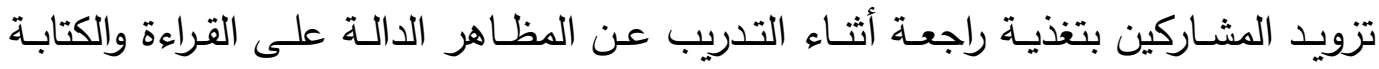

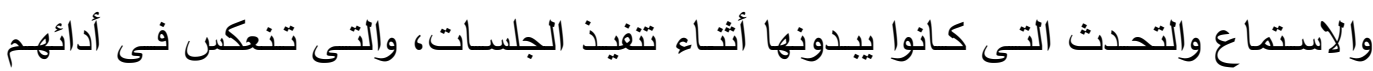
للواجبات المنزلية.

\section{ثانياً : نتائج الفرض الثاني:}

ينص الفرض الثاني على: "توجد فروق دالة إحصائياً بين متوسطي درجات تلاميذ المجموعة التجريبية فى القياسين البعدي والتتبعي".

وللتحقق من هذا الفرض تم استخدام اختبار "ت" (Paired Samples T Test) عينات مرتبطة، والجدول التالي يوضح ذلك.

\begin{tabular}{|c|c|c|c|c|c|c|c|c|}
\hline الثلالة & "تئة & التأثير & العرية & العباري & الهترسط & | الإزراد & القياس & القرانية \\
\hline \multirow{2}{*}{ : } & \multirow{2}{*}{$-1 . \cdot$} & \multirow{2}{*}{$\because 1$} & \multirow{2}{*}{19} & Y.M & 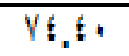 & $\Gamma_{1}$ & البداى & \multirow{2}{*}{ رالقهب القرائي التعرن } \\
\hline & & & & Y.Y! & 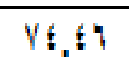 & $\mu_{1}$ & التتببي & \\
\hline \multirow{2}{*}{ (r } & \multirow{2}{*}{1.06} & \multirow{2}{*}{$\because \mu$} & \multirow{2}{*}{ Yq } & 1.00 & 97.4 & $r \cdot$ & البكاى & \multirow{2}{*}{ القران التطقي } \\
\hline & & & & 1.04 & 10.9. & r. & التتببي & \\
\hline \multirow{2}{*}{$\because \%$} & \multirow{2}{*}{1.71} & \multirow{2}{*}{ 4: } & \multirow{2}{*}{ Yq } & 7.0 & 119.01 & $r_{1}$ & البدى & \multirow{2}{*}{ ألثرية الكلية } \\
\hline & & & & 5.1. & $11, . \mathrm{NV}$ & $r$. & التتببي & \\
\hline
\end{tabular}

يتضح من الجدول السابق أن قيمة "ت" للفروق بين متوسطى درجات القياسين البعدى والتتبعي فى مهارات التعرف والفهم القرائي ومهارات النطق القرائي والدرجة الكلية غير دالة لئل 
إحصائياً بين القياسين البعدى والتتبعي، كما يتضح من الجدول السابق وجود حجم أثر منخفض

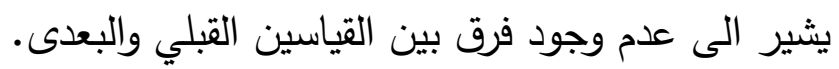
وبالتالي يتم رفض الفرض الثاني حيث لا توجد فروق دالت التئ إحصائياً بين متوسطي درجات تلاميذ المجموعة التجريبية فى القياسين البعدي والتتبعي.

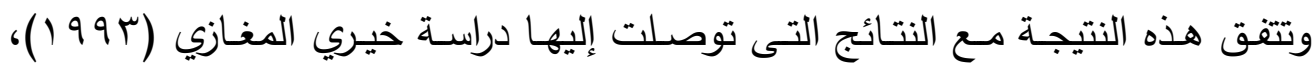

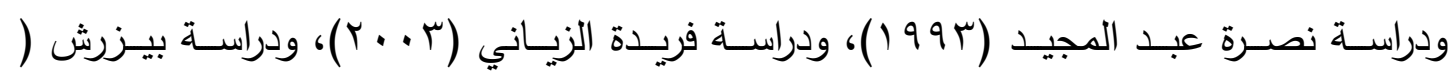

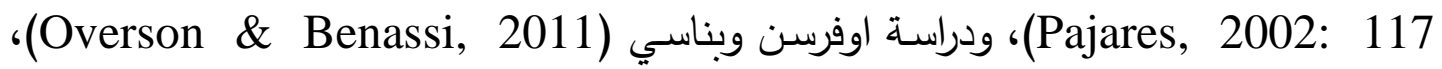

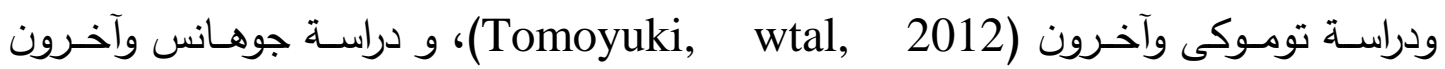

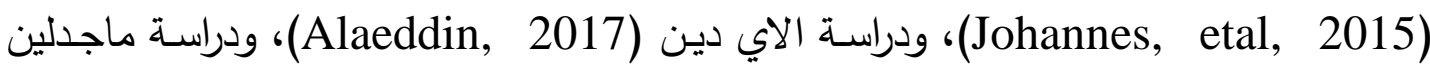

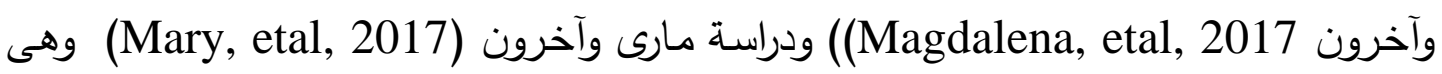
عدم وجود فروق بين القياسين البعدي والتتبعي لدي تلاميذ المجموعة التجريبية بعد تطبيق البرنامج التدريبي.

وتفسر الباحثة عدم وجود فروق بين القياسين البعدي والتتبعي في المهارات القرائية

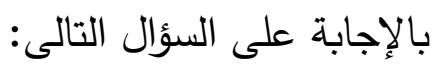
لماذا لا توجد فروق دالة إحصائياً بين متوسط درجات القياسين البعدي والتتبعي في المهارات القرائية لاى تلاميذ الصف الرابع الابتدائي ذوى العسر القرائي دئي؟ وتفسر الباحثة ذلك فى ضوء مايلي: عدم وجود فروق بين القياسين البعدي والتتبعي يشير إلي بقاء اثر التعلم لدي تلاميذ

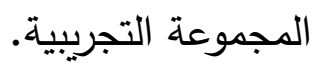
تشير هذه النتيجـة الي استفادة تلاميذ المجموعـة التجريبيـة مـن البرنـامج التدريبي اثنـاء الجلسات المقدمه لهم وتفاعلهم معها. تعرض المجموعة التجريبية للقياس البعدي والقياس التتبعي بعد تطبيق البرنامج، أدي إلي عدم وجود فروق بين القياسين، وهذا يشير إلي نجاح البرنامج في تحقيق أهدافه.

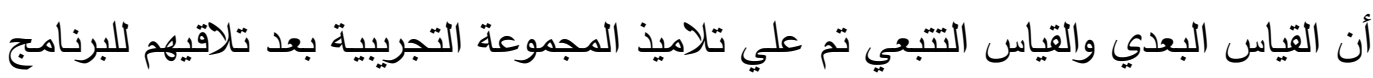

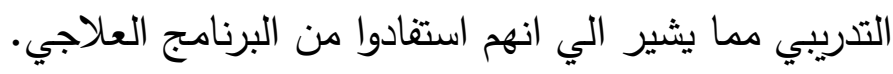


اهتمام تلاميذ المجموعة التجريبية باستكمال الجلسات التدريبية، أدي إلي تفوقهم في نهاية

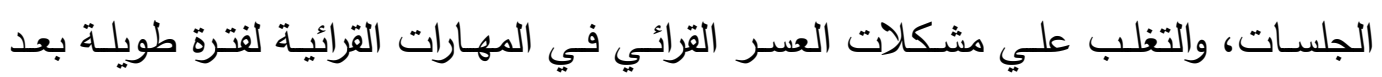

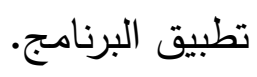

فى ضوء الدراسة الحالية تقدم الباحثة التوصيات التالية:

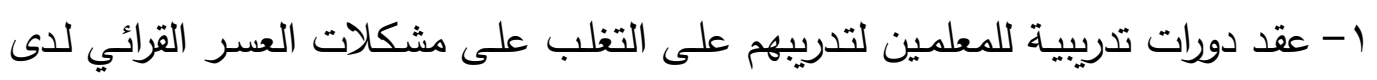

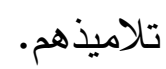
r- التركيز على أهمية وجود تعليمات واضحة عند استخدام برامج تدريبية تتضمن وصفاً للأساليب والإجراءات الواجب اتباعها بما يساعد المتعلمين على التعامل معها.

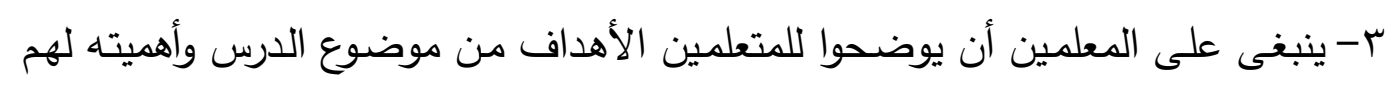

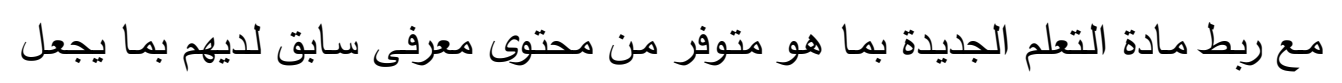
مادة التعلم الجديد ذات معنى يساعد على تتمية مهارات القراءة.

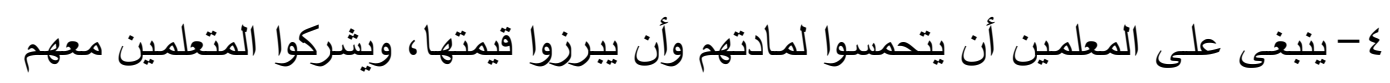

$$
\text { فى إعداد الدرس أو شرحه أو توزيع الأوراق. }
$$

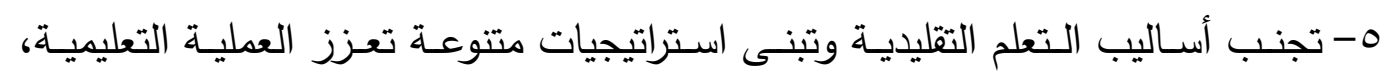

$$
\text { وتكسب المهارات والخبرات اللازمة للتعلم. }
$$

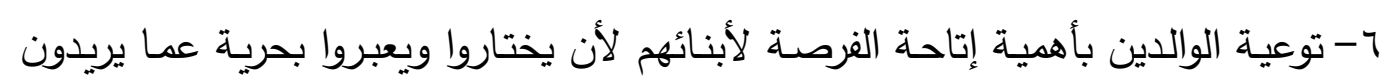

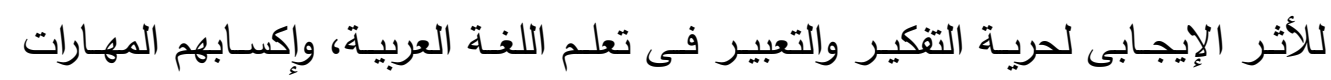

$$
\text { الاجتماعية والإبداعية. }
$$

V-توعية أولياء الأمور والمعلمين بضرورة تثجيع الأبناء على القراءة والكتابة والاستماع

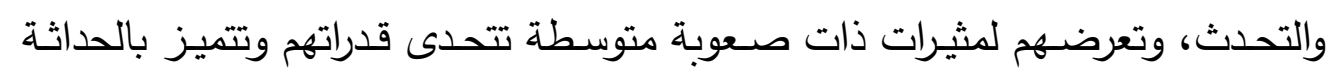
والجدة والتعارض، مع إتاحة الفرصة لهم لاختيار الأنشطة التى يحبون أن يمارسوها؛ لأنها تحسن دافعيتهم لتعلم اللغة العربية ومهاراتها.

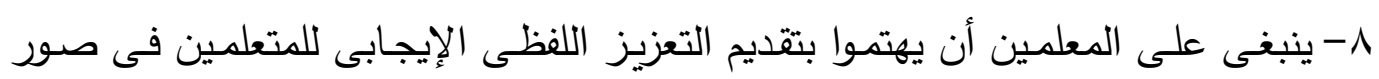

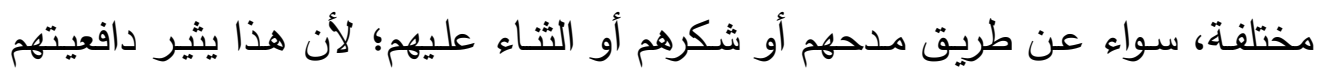

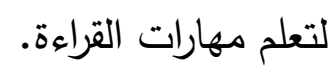


9- تضمين المناهج أو المقررات الدراسية بعض الألغاز أو المشكلات أو الصور، تحثهم على القراءة والكتابة والاستماع والتحدث باللغة العربية.

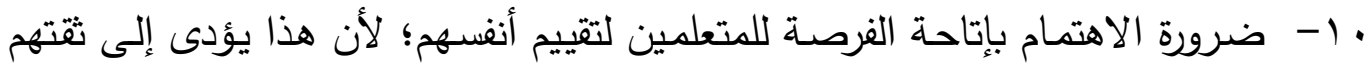
بأنفهر، الأمر الذى يؤدى إلى التغلب علي مشكلات العسر القرائي لدى التلاميذ.

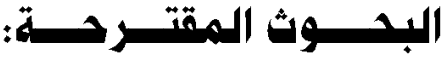

1- أثر برنامج علاجي قائم على بعض أنواع الذكاءات المتعددة فى علاج صعوبات تعلم

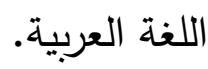
ץ- أثر برنـامج علاجي قـائم على بعض استراتيجيات التعلم المـنظم ذاتياً فى التفكير

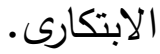

r- أثر استراتيجيات تجهيز المعلومات فى تتمية المهارات القرائية لدى التتلاميذ ذوى العسر القرائي فى المرحلة الابتدائية.

ع - العلاقة بين بعض أنواع الذكاءات المتعددة وبعض استراتيجيات التعلم المنظم ذاتياً. ه- أثر استخدام استراتيجيات التعلم المنظم ذاتياً فى التغلب على مشكلات العسر التعراء الترائي

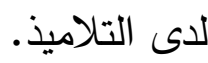
צ- أثر برنامج قائم على بعض استراتيجيات التعلم المنظم ذاتياً فى التحصيل الدراسى فى

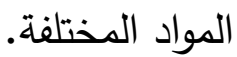

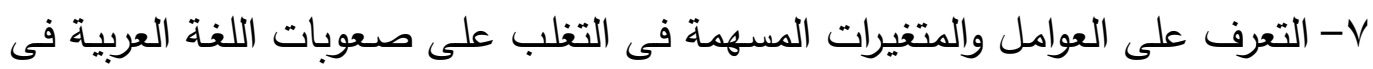

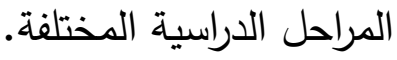




\section{المــــاجـ}

المراجع العربى

• جابر عبدالحميد. ( 1999 ). استراتيجيات التدريس والتعلم. سلسلة المراجع فى التربية وعلم النفس، الكتاب العاشر. القاهرة: دار الفكر العربى.

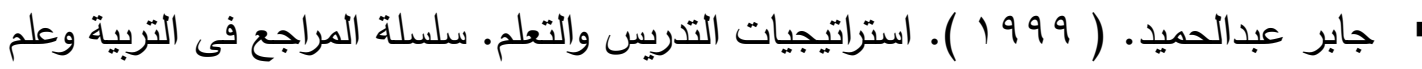

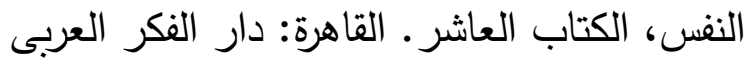

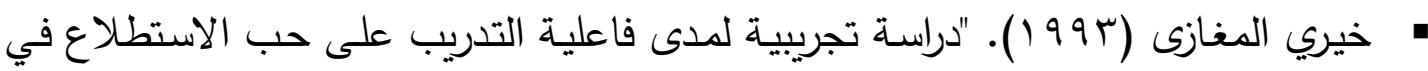

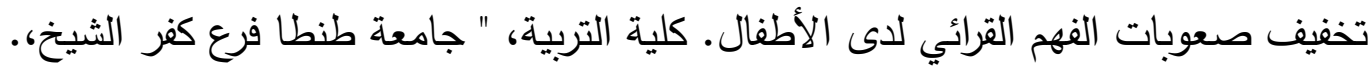

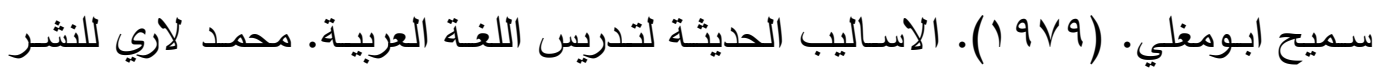
والتوزيع.

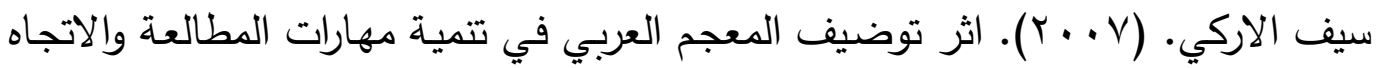

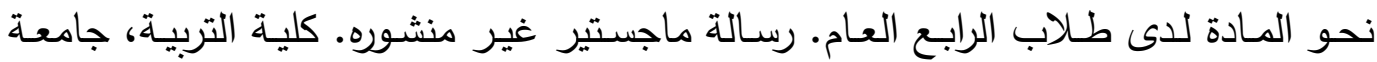
ديالى.

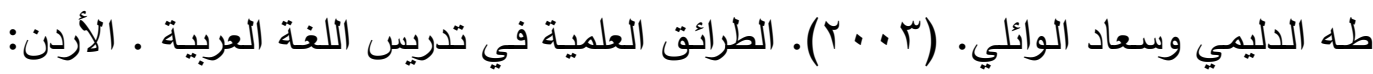
دار الثروق

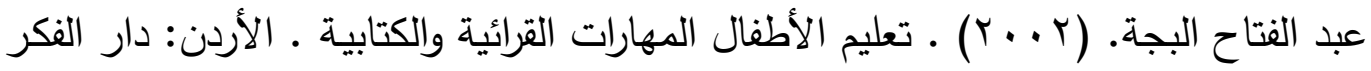

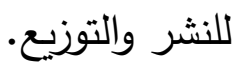
عتمان (• (199). صعوبات التعلم، القاهره، مكتبه الأنجلو المصريه

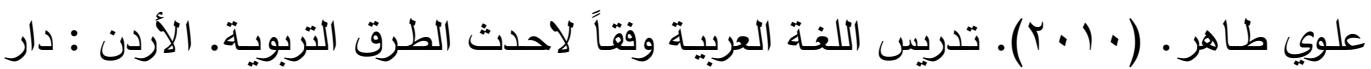

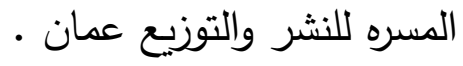

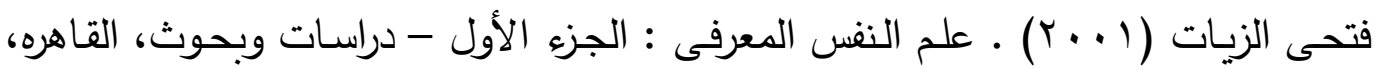

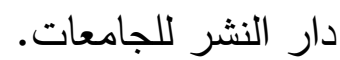
فتحى الزيات(991 (1) "صعوبات التعلم والأسس النظريه والتشخيصيه والعلاجيه "دار النشر لمجامع، القاهره، طا.

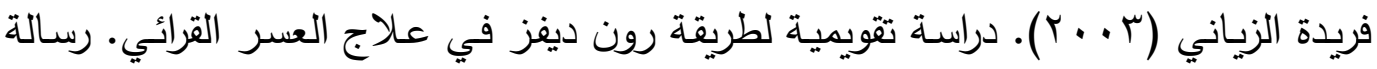
ماجستير غير منشورة. معهة البحوث التربوية، جامعة القاهرة. 


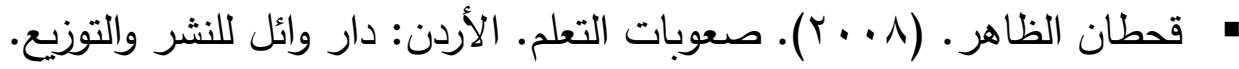

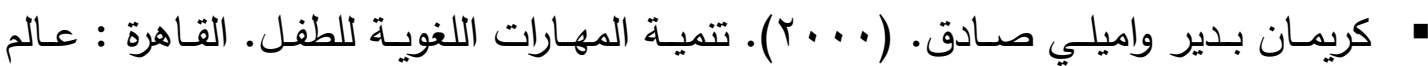
الكتب.

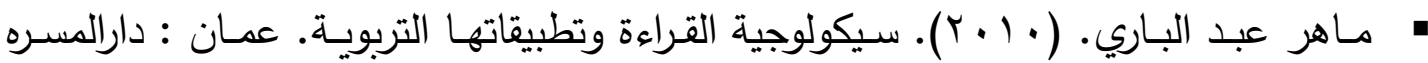
للنشر والتوزيع والطباعة.

• محمود الجومرد. (rا197). الطرق العلمية لتدريس اللغة العربية. العراق : مطبعة الهدف.

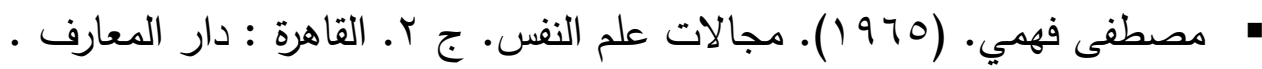
• نصرة جلجل (ب991). تشخيص العسر القرائي غير العضوي لاى عينة من تلاميذ الحلقة الأولى من التعليم الأساسي مع فاعلية برنامج علاجي مقترح. رسالة دكتوراه غير منشورة.

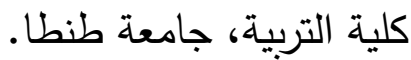
يوسف قطامى ( • 99 ().فاعليه برنامج مقترح قائم على نظريه الذكاءات المتعددة فى تتميه بعض المفاهيم العلميه ومهارات الأستقصاء العلمى فى مادة الأحياء لاى طلاب المرحله الثانويه، رساله اجستير غير منشوره، كليه التربيه، جامعه كفر الثيخ

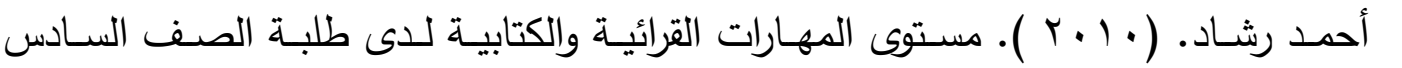
وعلاقته بتلاوة وحفظ القرآن الكريم. رسالة ماجستير غير منشورة. كلية التربية، الجامعة التهادية

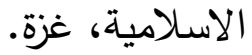

\section{المراجع الأجنبى}

- Metacognitive Functioning, Self-Efficacy, and Study Behavior. Ph.D, University of New Hampshire, 3467354.

- Alaeddin K. (2017). Do Multiple Intelligences Improving EFL Students' Critical Reading Skills?, Arab World English Journal (AWEJ) Volume.8 Number.1 March, 2017 Pp. 309- 321.

- Antje S. Ross A. Catherine G. \& Anika F. (2015). Reading and spelling skills in German third graders: Examining the role of student and context Characteristics, British Journal of Educational Psychology (2015), 85, 533-550.

- Boekaerts, M. (1999). Self-regulated learning: Where we are today?. International Journal of Educational Research, 31, 6, 445-457. 
- Boyle,1996 Emergent, Self-Directed, and Self-Organized Learning: Literacy, Numeracy, and the iPod Touch, International Review of Research in Open and Distance Learning, v12 n7 p135-146 Nov 2011. $12 \mathrm{pp}$

- Henderson, R. W., \& Cunningham, L. (1994). Creating interactive sociocultural environments for self-regulated learning. In D. H. Schunk \& B. J. Zimmerman (Eds.), Self-regulation of learning and performance: Issues and educational applications (pp. 255-281). Hillsdale, NJ: Lawrence Erlbaum.

- Jessica K. Anna W. Penny L. Deborah D. Stephen R. Jane E. Donald B. (2015). Reading and Phonological Skills in Boys with Fragile X Syndrome, J Autism Dev Disord (2015) 45:1699-1711 DOI 10.1007/s10803-014-2328.

- Linder. R and Harris. B (1993). Self Regulated Learning Meta Cognition and the Problem of Transfer. Paper Presented at the 4th International Correction Education Association Annual Conference. July 12.Chicago

- Magdalena K. Katrin D. Florian B. Dajie Z. Karin L. Christof K. Franz P. Thomas P. Christa E. Peter B. (2017). Eye Movements during Silent and Oral Reading in a Regular Orthography: Basic Characteristics and Correlations with Childhood Cognitive Abilities and Adolescent Reading Skills, PLoS ONE 12(2): e0170986. doi:10.1371/journal.pone.0170986

- Paris, S. G., Byrnes, J. P., \& Paris, A. H. (2001). Constructing theories, identities, and actions of self-regulated learners. In B. J. Zimmerman \& D. H. Schunk (Eds.), Self-regulated learning and academic achievement: Theoretical perspectives (2nd ed., pp. 253288). Mahwah, NJ: Lawrence Erlbaum

- Perry, W. Jr. (1981). Cognitive and ethical growth: The making of meaning. In A. Chickering (Ed.), The modern American college (pp. 76-116). San Francisco: Jossey-Bass

- Sarah P. Cara O. Lynne G. (2016). Understanding children's reading activities: Reading motivation, skill and child characteristics as predictors, Journal of Research in Reading, ISSN 0141-0423 DOI:10.1111/1467-9817.12060 Volume 39, Issue 1, 2016, pp 109125. 
- Swanson, H.(1987)"Information processing theory and learning disabilities":An

- Vickie P. Michel B. Nadine F. Mara B. Frank V. Cecilia M. Richard T. \& Ginette D. (2015). Phenotypic and genetic associations between reading comprehension, decoding skills, and ADHD dimensions: evidence from two population-based studies, Journal of Child Psychology and Psychiatry 56:10 (2015), pp 1074-1082

- Winne, P. H., \& Hadwin, A. F. (1998). Studying as self-regulated learning. In D. J. Hacker, J. Dunlosky, \& A. C. Graesser (Eds.), Metacognition in educational theory and practice (pp. 277-304). Hillsdale, NJ: Lawrence Erlbaum.

- Zimmerman, B. (1994). Dimensions of Academic Self-Regulation: A Conceptual Framework for Education. In D. Schunk \& B. Zimmerman (Eds). Self-Regulation of Learning and Performance: Issues and Educational Applications.(p. 1-19). NJ. Lawrence Erlbaum Associates.

- Zimmerman, B. (2000). Attaining self-regulation. Boekaerts, P. Pintrich, \& M. Zeidner (Eds.),Handbook of self-regulation. (p. 1339). NY. Academic Press. 


\section{Abstract}

The last decades of the past century have witnessed a remarkable development in the field of teaching, and attention to information is no longer the sole purpose of the educational process has significantly increased interest in the pupil by encouraging him to film more actively and interacting with his colleagues as a group as individuals, and to be given the opportunity to learn how to deal with others so that they can be more capable of belonging to the group, and in supporting the links between them and their peers than it leads to social skills and literacy skills, where the (reading) of the communication skills on which many are built Learning skills, Mastery helps students to acquire the science, knowledge and skills that the teacher, the family and the community seek to impart to the individual., and helps the student communicate better with the community, and any weakness, or dysfunction (reading), is followed by a weakness in learning and other skills

The difficulties of learning are related to the negative consequences of the problem of the burden and the lack of the ability to preach and other problems that are reflected in various disorders and negative behaviours such as dropping out of education, the phenomenon of the Rob machine or the educational loss.

The present study attempts to identify the impact of self-managed learning in the development of literacy skills for the fourth grade special hardship 